Florida International University

FIU Digital Commons

\title{
A Phenomenological Study on Self-Efficacy and Self-Regulated Learning Strategies and their Link to Persistence in Hispanic College English Language Learners
}

Gabriela DeFrancisco

Florida International University, gdefr001@fiu.edu

Follow this and additional works at: https://digitalcommons.fiu.edu/etd

Part of the Adult and Continuing Education Commons, Bilingual, Multilingual, and Multicultural Education Commons, and the Higher Education Commons

\section{Recommended Citation}

DeFrancisco, Gabriela, "A Phenomenological Study on Self-Efficacy and Self-Regulated Learning Strategies and their Link to Persistence in Hispanic College English Language Learners" (2019). FIU Electronic Theses and Dissertations. 3950.

https://digitalcommons.fiu.edu/etd/3950

This work is brought to you for free and open access by the University Graduate School at FIU Digital Commons. It has been accepted for inclusion in FIU Electronic Theses and Dissertations by an authorized administrator of FIU Digital Commons. For more information, please contact dcc@fiu.edu. 


\section{FLORIDA INTERNATIONAL UNIVERSITY \\ Miami, Florida}

\section{A PHENOMENOLOGICAL STUDY ON SELF-EFFICACY AND SELF-REGULATED LEARNING STRATEGIES AND THEIR LINK TO PERSISTENCE IN HISPANIC COLLEGE ENGLISH LANGUAGE LEARNERS}

A dissertation proposal submitted in partial fulfillment of the

requirements for the degree of

DOCTOR OF EDUCATION

in

ADULT EDUCATION AND HUMAN RESOURCE DEVELOPMENT

by

Gabriela De Francisco

2019 
To: Dean Michael R. Heithaus

College of Arts, Sciences, and Education

This dissertation, written by Gabriela De Francisco and entitled A Phenomenological Study On Self-Efficacy and Self-Regulated Learning Strategies and Their Link to Persistence in Hispanic College English Language Learners, having been approved in respect to style and intellectual content, is referred to you for judgment.

We have read this dissertation and recommend that it be approved.

Teresa Lucas

$\begin{array}{r}\hline \text { Joanne Sanders-Reio } \\ \hline \text { Tonette S. Rocco } \\ \hline \text { Thomas G. Reio, Jr., Major Professor }\end{array}$

Date of Defense: March 20, 2019

The dissertation of Gabriela De Francisco is approved.

Dean Michael R. Heithaus

College of Arts, Sciences and Education

Andres G. Gil

Vice President for Research and Economic Development and Dean of the University Graduate School

Florida International University, 2019 
C Copyright 2019 by Gabriela De Francisco

All rights reserved. 


\section{DEDICATIONS}

I would like to dedicate this dissertation to God, for always being there for me, especially in my toughest moments. I will also be forever grateful to my grandparents, my mother, father, and godfather Orlando who never stopped believing in me and supporting me until the very end of their lives. I know you are still with me always in Heaven as my guardian angels. My godmother, Ana Celia has always been unwavering in her support and has pushed me to continue despite all the of the challenges that came my way. She has been another mother to me and continues to be my cheerleader. My sister, Mariana is a role model of strength in the face of adversity with her illness, My best

friend, Jose, whom I can never thank enough for believing in me and helping me to reach my goals. Finally, my daughter Kassandra and my grandchildren Nathalia, Nicole, Valentina, and Jonathan whom I love with all my heart and make me want to be a better person. 


\section{ACKNOWLEDGMENTS}

I would like to acknowledge my committee members, Dr. Thomas Reio, Dr. Tonette Rocco, Dr. Joanne Sanders-Reio, and Dr. Teresa Lucas for expecting the best from me and providing their guidance throughout this difficult process. Dr. Reio has not just been my advisor, he has been my mentor and a friend who refused to let me quit. I could always count on his advice and his pep talks. My nephews Henry and Orlando helped me prepare for my defense and provided support. I would like to thank my participants because they trusted me to tell their stories, and I gained a new perspective from them sharing their experiences with me. I appreciate the advice and pointers I received from Fabiana Brunetta on the graduation process and dissertation defense. Finally, my best friend, Jose Otero always motivated me to never give up, and would keep me company while I studied for my classes and worked on my dissertation. I would like to thank all of these individuals from the bottom of my heart because I would not have been able to complete this journey without them. 
ABSTRACT OF THE DISSERTATION

A PHENOMENOLOGICAL STUDY ON SELF-EFFICACY AND SELF-REGULATED

LEARNING STRATEGIES AND THEIR LINK TO PERSISTENCE IN HISPANIC

COLLEGE ENGLISH LANGUAGE LEARNERS

by

Gabriela De Francisco

Florida International University, 2019

Miami, Florida

Professor Thomas G. Reio, Jr., Major Professor

In adult education, studies have been done in the areas of persistence, selfefficacy, self-regulated learning strategies and the Hispanic population. However, this study was unique in its attempt at examining the link between the academic self-efficacy and self-regulated learning strategies in the persistence of Hispanic college English language learners. The purpose of this phenomenological study was to understand the experience of $1^{\text {st }}$ generation Hispanic English Language learners during their first year at a Hispanic-Serving Institution. 
The researcher conducted 14 semi-structured interviews of their experiences both as immigrants learning the English language and first-generation college students by utilizing a phenomenological framework. The study served two purposes: (a) informing the literature and (b) supporting the necessity for helping facilitate the path to higher education for first-generation Hispanic college students. Five themes emerged from the data related to persistence among the participants: (a) families and teachers encourage goal-setting and motivation, (b) the power of motivation in the pursuit of the seemingly elusive American Dream, (c) difficulties in navigating the higher education system as first-generation college students, (d) friendships and the role they play in the participants' lives, and finally, (e) uncertainty of the future and participants' expectations after graduation.

Theoretical, empirical, and practical implications related to persistence among $1^{\text {st }}$ year Hispanic students are explored. In particular, these findings highlight the need for future research that informs existing theoretical models of student persistence and the practical utility of attending to learners' needs early in the collegiate experience. 


\section{TABLE OF CONTENTS}

CHAPTER $\quad$ PAGE

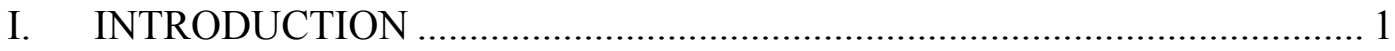

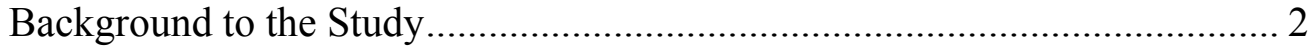

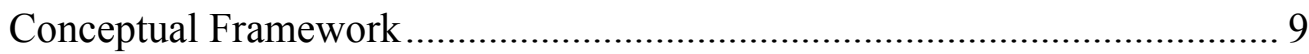

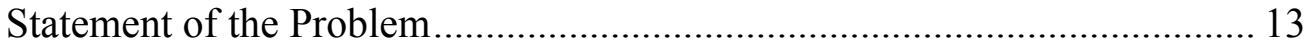

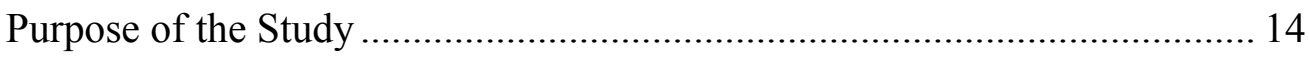

Research Questions ......................................................................... 15

Significance of the Study .............................................. 16

Limitations and Delimitations of the Study................................16

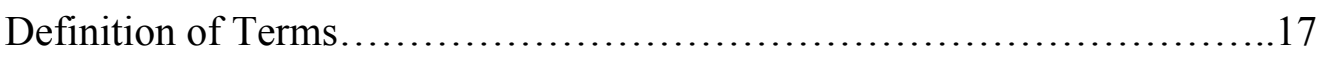

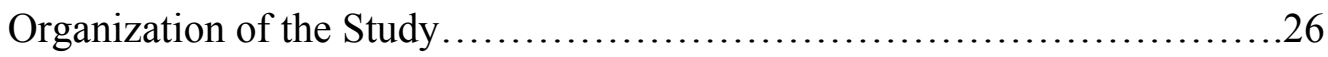

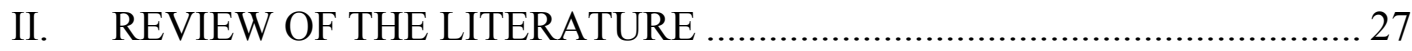

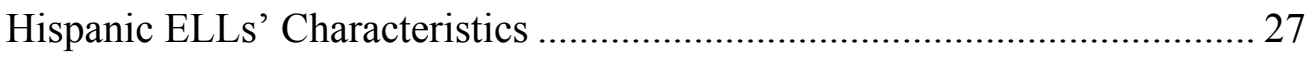

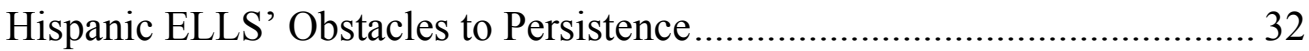

Self-Efficacy, Self-Regulated Learning Strategies and Persistence ............... 36

Bandura's Social Cognitive Theory ............................................................. 40

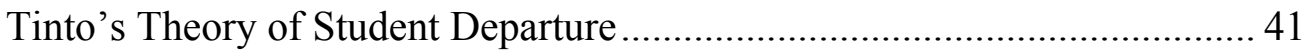

Astin's Theory of Student Involvement.................................43

Application to Higher Education......................................43

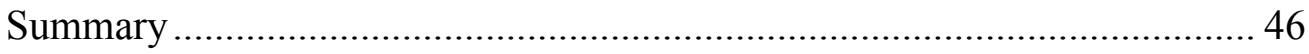

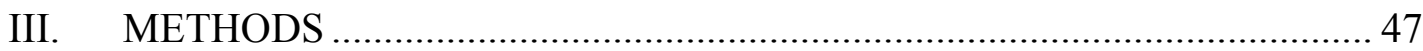

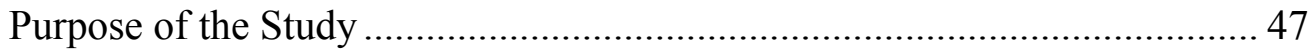

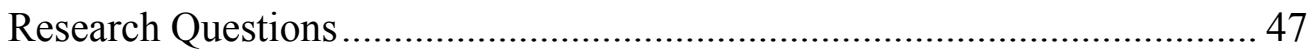

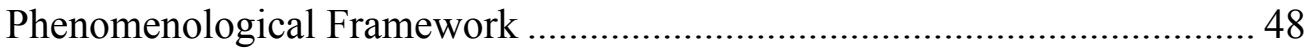

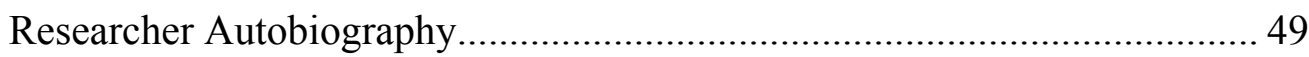

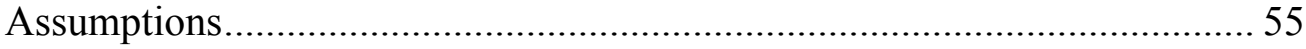

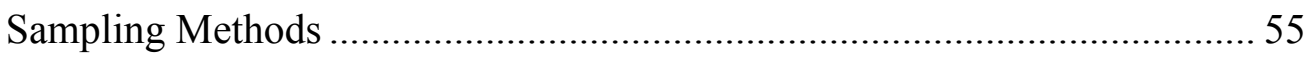

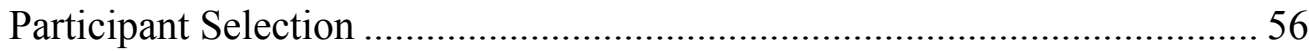

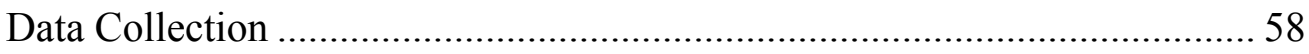

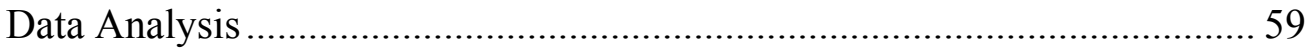

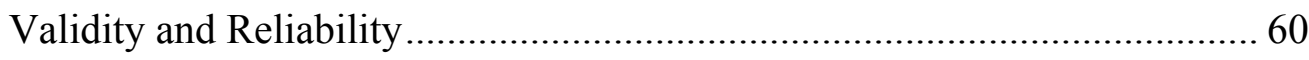

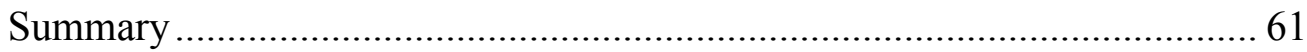

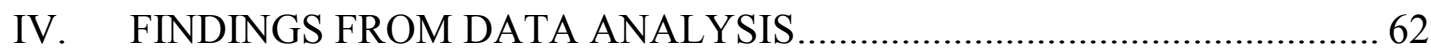

Families and Teachers Encourage Goal-Setting and Motivation ................... 62 
The Power of Motivation in the Pursuit of the American Dream................. 67

Difficulties in Navigating the College System ......................................... 74

The Role of Friendship........................................... 81

Facing an Unknown Future.......................................... 84

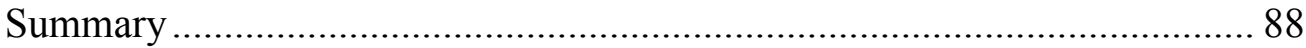

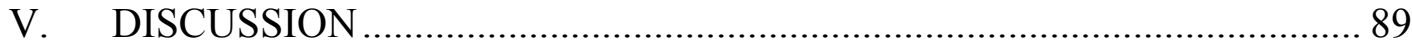

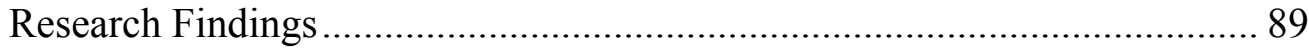

Theoretical Implications........................................93

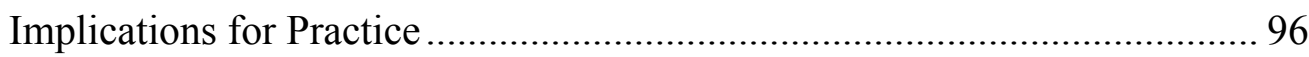

Limitations and Recommendations for Future Research........................... 99

Summary..................................................... 101

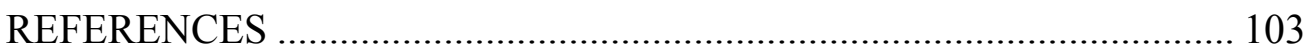

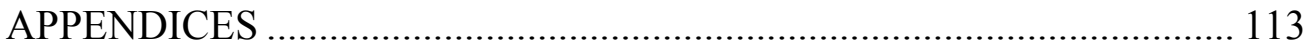

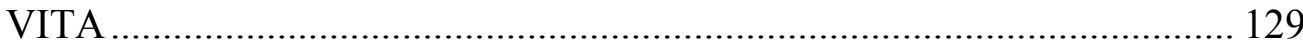




\section{CHAPTER I INTRODUCTION}

The lack of persistence to college graduation for Hispanic College English Language Learners in higher education institutions is a major problem today in areas of the United States where there is a heavy concentration of immigrants and first-generation Americans (Arana, Castaneda-Sound, Blanchard, \& Aguilar, 2011; Baum \& Flores, 2011; Conway, 2010; D’Lima, Winsler, \& Kitsantas, 2014). According to the 2010 Census Bureau, Hispanic or Latino is defined as "a person of Cuban, Mexican, Puerto Rican, South or Central American, or other Spanish culture or origin regardless of race" (p. 2). Lack of persistence is a problem because it does not break the cycle of poverty. Gofen (2007) has found that education is a major route to social mobility. According to The Condition of Education Act of 2014, 33\% of Hispanic children 18 years of age and under live in poverty, with Florida being one of the states with higher than average poverty rates in school age children. In addition, Florida is one of the fourteen states in which English Language Learner (ELL) public school enrollment was between 6.0\% and 9.9\% during the 2011-12 school year, with only eight other states such as California and Texas having a $10 \%$ or more enrollment of ELLs.

According to Kenia and Lizzio (2008) the lack of academic self-efficacy and selfregulated learning strategies are an impediment for first-generation students to achieve their goals and consequently, persist (D’Lima, Huie, Winsler, \& Kitsantas, 2014; Zimmerman, 2008). Researchers Crisp and Nora (2009) found that for student persistence to take place among Hispanic first-generation students, the formula should include 
academic preparation before college, academic experiences during college, sociocultural capital, positive environmental influences, and attending a HSI (Hispanic Serving Institution). Student persistence for the purposes of this research will be defined as enrollment in the following semester (Tinto, 1993). Because research has demonstrated that goal-setting, student involvement in school activities, student interaction with peers and faculty members, study environment, and the use of self-regulated learning strategies are linked to persistence in general (Dinther, Dothe, \& Seger, 2010; Duque, 2013; Liao, Ferdenzi, \& Edlin, 2012; Zimmerman, 2008), this research will examine possible links to freshman persistence among ELLs.

\section{Background of the Study}

Hispanic College English Language Learners in Texas, Florida, California, Illinois, New Jersey, and Arizona face difficult challenges such as the language barrier, lack of sociocultural competence, and financial hardships in their quest to obtain a college degree (Bliss \& Sandiford, 2003; Fiebig, Braid, Ross, Tom, \& Prinzo, 2010; Gonzalez, 2010). Most of these students are nontraditional; they are older, selfsupporting, have children, work full-time, and study part-time (Kenner \& Weinerman, 2011; Nakajima, Dembo, \& Mossler, 2012). According to Knowles and other adult education researchers, the characteristics of the adult learners need to be considered to make instruction more effective (Kenner \& Weinerman, 2011; Knowles, 1974). Schraw and Moshman (1995) state that there are three frameworks that explain how adult learners adapt to the higher education environment, which are informal theory, formal theory, and tacit theory. Formal theories "consist of highly systematized accounts of a 
phenomenon involving explicit theoretical structures such as those encountered in university classes in physics, music, or statistics" (Schraw \& Moshman, 1995), and are employed solely in academia; because we are discussing students with at least one nontraditional characteristic (e.g., working part-time, working full-time, delayed enrollment, financially independent, single parent, have children or dependents other than spouse) who are returning to education, it does not play a role in this circumstance. However, both tacit theory and informal theory do inform us how adult learners utilize their metacognition (awareness of how one learns) to acquiring new information and adapting it for their own purpose. Tacit theory is defined as the lack of awareness of a theory regarding one's learning process (McCutcheon, 1992). The difference between tacit theory and informal theory is that in the former, the individual has no awareness of possessing a learning theory, whereas in the latter the individual has some awareness, even though it is not complete (McCutcheon, 1992).

Andragogy, the art and science of helping adults learn, stresses the need to take the adult learner's background knowledge and skills into account (Knowles, 1974). This is also stressed in pedagogy, which is education methodology geared to children, but it is more vital when the learners are adults. The adult learner is searching for meaning or a purpose to the new skills and information being acquired. The central tenets of andragogy, as developed by Malcolm Knowles (2012) and based on the original theories of Eduard Lindeman, are: “(1) the learner's need to know, (2) self-concept of the learner, (3) prior experience of the learner, (4) readiness to learn, (5) orientation to learning, and (6) motivation to learn" (Knowles, 1980, p. 3). For example, adult learners need to find the utility in a course and understand the objectives, or it will not facilitate persistence 
(Kenner \& Weinerman, 2011). Strategies like reviewing a detailed syllabus and the instructor's expectations for the course, and how the learners can adapt the materials to their unique style of learning is how "framing" takes place. Framing takes place when instructors teach lessons with the usefulness of the material to the adult learners' needs in mind (Knowles, 1984). Other strategies such as repetition and competition must also be taken into consideration in andragogy. For example, the same concept can be presented in more than one way (repetition), so that the adult learner acquires the knowledge. The strategy of competition is one in which the learner's background knowledge is compared with the new strategy being taught, and the learner can understand the commonalities and differences between them. To illustrate, a wise instructor teaching research paper writing for the first time, would compare it to a type of writing assignment the students have done before, like essay writing. In this manner, the students can determine what the similarities and differences are. By utilizing their prior knowledge, it will be much easier for them to comprehend the assignment (Kenner \& Weinerman, 2011).

It is essential to understand how adults learn because most Hispanic ELLs are nontraditional, older students, and primarily first-generation Hispanics. Due to this firstgeneration status, some of them are undocumented and have a low socioeconomic status (SES). Being a first-generation Hispanic student, having a low SES, working full-time, and being older all are risk factors associated with persistence (Arana, Castaneda-Sound, Blanchard, \& Aguilar, 2011; Carter, 2006; Nakajima, Dembo, \& Mossler, 2012). As firstgeneration college students, ELLs are left to navigate financial aid issues and other higher education issues on their own because they are the first ones in their family to have persisted beyond a high school education. This lack of exposure to the culture of the 
American college system leaves them lacking in cultural capital. "Cultural capital refers to preexisting knowledge about interacting successfully in college settings" (Collier \& Morgan, 2007, p. 429), which is associated with persistence in college (Arana et al., 2011). Despite the obstacles against them, researchers have found that ELLs aspire for persistence (Conway, 2010). However, many must drop out of college because of their family and work obligations (Arana et al., 2011).

Most ELLs attend community colleges because they are more economical, more accessible, and offer English for Speakers of Other Languages (ESOL) programs (Chang, 2005). When ELLs apply to these colleges, they are evaluated on their language proficiency and placed into levels, which range from Level 1 (Beginner) to Level 6 (Highly Proficient). Upon completion of all six levels, these students should be prepared to commence their studies in their chosen major. The students are not awarded credit towards graduation for the English for Academic Purposes (EAP) classes nor for any remedial classes they have taken. Unfortunately, research studies have seen a link between taking remedial classes and lack of persistence, especially when there is a lack of English proficiency (Almon, 2015; Nakajima et al., 2012). Community colleges have an open access policy, but these institutions regularly place more than a third of their students in remedial classes (Barbatis, 2011). Although students may be better prepared academically, they often feel discouraged because of the time and expense of taking noncredit courses (Barbatis, 2011; De La Cruz, 2008; Vassilou, 2011). Even if ELLs are not required to take any EAP or remedial courses, they may lack academic language proficiency and cultural capital (Chang, 2013). ELLs and college freshmen are often at a loss with academic language because academic language possesses a unique vocabulary 
and syntax which needs to be mastered so that the student may succeed in college (Coffman, 2011).

A lack of cultural capital is another barrier for ELLs. ELLs as first-generation students lack cultural capital because of the difficulties they possess with navigating through the college process of financial aid, college applications, expectations, and even the role of a college student (Collier \& Morgan, 2007). In addition, ELLs may feel unwelcome in the college or university environment because the student organizations do not promote diversity (Espinosa, 2013; Gloria \& Rodriguez, 2000; Nakajima, Dembo, \& Mossler, 2012). With all these challenges, it is not surprising that many ELLs drop out, even though most of them aspire to graduate from college (Baum \& Flores, 2011; Gonzalez, Stein, \& Huq, 2012).

The need to support ELLs through graduation and beyond is in everyone's best interests. If this student population can persist through college, they will benefit from greater opportunities for employment and improve the lives of their children and grandchildren. An investment in ELLs' education significantly impacts their futures for generations because research indicates that the likelihood of first generation students dropping out is 8.5 times greater than students whose parents went to college (Baum \& Flores, 2011; Ishitani, 2006).

Moreover, the United States would benefit by not having to import talent from other nations, and by decreasing the amount of governmental assistance it must provide (Espinoza, 2013; Kesici, \& Erdogan, 2009). The number of Latinos and other minority populations are growing in the United States, and it is the country's responsibility to 
support these new residents by providing guidance and support in institutions of higher learning (Baum \& Flores, 2011; Coffman, 2011).

In 2001, President G. W. Bush enacted the No Child Left Behind law, which has had a tremendous impact on public K-12 education throughout the nation, for better or worse (Abedi, 2004). However, what happens when these adolescents graduate? High school diplomas and GEDs are basically tickets to a college education because secondary education alone is not sufficient to secure more than a minimum wage salary (Reeves \& Stich, 2011). While the Development, Relief, and Education for Alien Minors (DREAM) Act did appear in the U.S. Senate in 2001, it still has not been enacted officially, even though President Obama's 2012 policy changes favored it. Because this legislation did not pass, President Obama issued an executive order called Deferred Action for Childhood Arrivals (DACA), whose purpose is to defer deportation for those illegal immigrants under age 30 who wish to attend college or enter the military. DACA stipulates that the immigrants must have resided here since 2007 and have been under the age of sixteen at the time of arrival (Walters, 2017). A decision regarding DACA was supposed to have been reached by a March 6 deadline. However, the Supreme Court intervened, and DACA is still in effect. Under pressure from both the Democratic and Republican parties, President Trump has vacillated over his policy regarding the Dreamers. On April 24, 2018 Judge John Bates reversed President Trump's decision to end DACA, and this legislation has permitted the Dreamers to continue applying for DACA status (Status of DACA Legislation, 2018). 
Presently, the Dreamers who arrived in 2007 have been in the United States for almost eleven years. They have had more time than more recent immigrants to become acclimated to their new country, especially since they arrived as minors under the age of sixteen. However, the focus of this research is on the newer immigrants who arrived here as adults. These newer immigrants do not qualify for DACA, since they have not resided here since 2007 . For them there is a need to balance a demanding work and family schedule with academic responsibilities. Consequently, by not prioritizing higher education, the U.S. work force has become more unskilled and more dependent on foreign markets, especially in the STEM fields, like engineering (Coffman, 2011; Espinoza, 2013; Ishitani, 2006). Finally, there is a gap in the literature regarding the challenges that ELLs face in a post-secondary institution, even though their college enrollment and persistence is "at stake" (Almon, 2015, p. 461). Although I found 27 articles that addressed Hispanics in education, only eight addressed both Hispanics and persistence (Almon, 2015; Arana et al., Cadenas, Bernstein, \& Tracy, 2018; Carter, 2006; Kim, Chang, Singh, \& Allen, 2015; Torres \& Solberg, 2001; Tovar, 2015; \& Vega, 2016). Four articles discussed both Hispanics and academic self-efficacy (Gonzalez, Stein, \& Huq, 2012; Gonzalez, 2010; Liao, Ferdenzi, \& Edlin, 2012; Torres \& Solberg, 2001). Out of these, just one article, by Torres \& Solberg (2001), addressed the topic of Hispanics, academic self-efficacy, and persistence.

According to Tinto's theory of student departure, being incorporated into the college environment is what encourages college students to persist in school. They need reassurance that they fit in academically and socially (Nakajima, Dembo, \& Mossler, 2012; Tinto, 1997). In addition, students' GPAs are also linked to persistence (Liao, 
Ferdenzi, \& Edlin, 2012). Therefore, the classroom and college environment play important roles in both the areas of academics and socialization. For instance, faculty interaction with students significantly affects both their academic and social self-efficacy (Chang, 2005). For social involvement to occur, Tinto believes in student integration in college life. However, ELLs, who typically attend 2-year colleges, participate in student clubs and activities at a $20 \%$ level, in comparison to the participation rate of students at public (50\%), and private 4-year institutions (67\%) (Coley, 2000; Chang, 2005; Zacajova, Lynch, Espenshade, 2005; Tinto, 1993).

Researchers have found that academic self-efficacy, GPA, and persistence are significantly linked (Kesici \& Erdogan, 2009; Nakajima et al., 2012). In addition, academic self-efficacy, along with parental involvement significantly predicted academic success (Liao et al., 2012). Academic self-efficacy is intricately linked to persistence due to its effects on attitude, behavior, academics, acculturation, and socialization (Collier \& Morgan, 2007; Espinoza, 2013; Lopez, 2014).

\section{Conceptual Framework}

Tinto's theory of student departure has often been used as a model to predict persistence in four-year colleges. In his theory, Tinto emphasized that students' previous backgrounds in terms of socioeconomic status, family background, parents' educational levels, race, ethnicity, gender, and high school achievement all played significant roles in college persistence. In addition, a commitment to the institution as well as academic and social integration also factor into the persistence equation. (Astin, 1993; Conway, 2010; Najima, Dembo, \& Mossler, 2012; Tinto, 1993). 
According to Bandura's social cognitive theory, there is a "triadic relationship" between behavior, the personal sphere that includes cognitive, affective, and biological factors, and the external environment. These three areas interact reciprocally (Bandura, 1997, p. 6). It has been found that perceived self-efficacy, defined by Bandura (1997) as the "beliefs in one's capabilities to organize and execute the courses of action required to produce given attainments" (p. 3) in conjunction with metacognitive self-regulation is related to academic achievement (Bandura, 1997; Kesici, Erdogan, \& Kelesoglu, 2009; Kitsantas, Winsler, \& Huie, 2008). Goal-setting, task strategies, high self-efficacy and interest, together with self-monitoring and self-reflecting on performance all constitute self-regulation (Kitsantas, Winsler, \& Huie, 2008).

In addition, researchers have found that academic self-efficacy and metacognitive self-regulation are highly correlated to both academic achievement and persistence (Zimmerman, 2000; Zimmerman, 1995). Self-regulatory strategies include goal-setting, self-monitoring, and self-evaluation (Zimmerman, 2000). Because stress and fatigue can undermine the strategies' effects, these factors can be more of a concern than students' awareness of these strategies (Zimmerman, 1995). Moreover, the use of self-regulatory strategies need to be implemented in a personalized manner to be effective. Bliss and Sandiford (2003) recommend that long-range planning rather than daily time management be utilized by part-time students because they found it more effective due to the unexpected changes that can occur in their personal lives. Because ELLs tend to be part-time students, counselors and professors can assist them with this and develop their syllabi accordingly. A study by Reeves and Stich (2011) found that undergraduates enrolled in a class that taught self-regulated learning strategies became more self- 
confident as learners and encouraged student persistence. The course structure was conceptualized by Iran-Nejad's theory of self-regulation, and taught students how to apply self-regulated strategies to note-taking, creating questions from lecture notes, reading for comprehension, mnemonics, and concept-mapping (Iran-Nejad, 1990; Todd \& Stich, 2011).

Astin's student involvement theory discusses more of the social aspect of the college experience. According to Astin, a four-year college experience was not equivalent to a two-year college experience in terms of student involvement. The difference was so acute that it could lead to students dropping out from college (Astin, 1985). Astin stated that many studies concluded that students and faculty members at two-year institutions tend to be part-timers who do not devote extra time to the college beyond class time (Astin, 1985). In addition, he believes that the peer group exerts enormous influence on the academic and social integration of college students (Astin, 1993). Astin felt that cooperative learning would best meet the needs of the students because the students would feel the pressure of having to perform to the standards of the group (1993). The "peer effect" is also useful in determining how gender, SES, and ethnicity play important roles. Astin reached the conclusion that students enjoyed interacting with students who were like themselves in gender, ethnicity, and SES. In addition, faculty-student interaction was an effective determinant in students' integration into the college setting (Astin, 1993). Due to the significant influence of the peer group and faculty-student interaction on the achievement and persistence of college students, it is being included in the conceptual framework, along with Tinto's theory of student departure. 
Tinto's theory of student departure focused on the steps of separation, transition, and incorporation that students needed to take to feel like part of the campus culture. The students had to undergo this process to separate from their home environment and transition to a new environment with a new lifestyle, values, and people. Once the transition was made, the student felt that he or she was a valued member of the community (Milem \& Berger, 1997; Tinto, 1993). Although Tinto makes a valid point regarding student persistence, his entire theory does not apply to nontraditional students or students with nontraditional characteristics because they do not feel the need to acculturate as much as students living on campus do. However, they still need to acculturate, because the college environment differs enormously from the high school and work environment, with its own values, lexicon, and standards. Many minority students have trouble adjusting to this new environment, and fail to persist, especially in community colleges (Barbatis, 2010; Espinoza, 2013; Schwartz, Benet-Martinez, Knight, Unger, \& Zamboanga, 2014). For these reasons, Tinto's and Astin's combined model of persistence provides valuable insight into what is needed to assimilate into the college environment.

The model used for this study will combine Tinto's Student Departure and Astin's Persistence Models with Bandura's Social Cognitive Model and will represent how academic self-efficacy and self-regulation has an impact on persistence. The Persistence Model was modified because ELLs tend to be nontraditional students or students with nontraditional characteristics; therefore, they are usually not active in campus activities, fraternities, and sports. When ELLs socialize and interact with their peers and faculty members, they do so informally and meet for coffee and snacks between classes. They 
often interact with their peers for study sessions in the library and visit their instructors during office hours. However, most of their day is spent at work and with their family (Chang, 2005; Kenner \& Weinerman, 2011; Trevino \& DeFreitas, 2014; Zalaquett, 2005). In contrast, Astin incorporates the college social scene into his model which is based on traditional students who attend four-year institutions (Astin, 1993; Pascarella \& Terenzini, 1981).

\section{Statement of the Problem}

English Language Learners of all ethnicities encounter hurdles of various types in their pursuit of higher education, such as the language barrier, financial difficulties, lack of familial support, and having to juggle too many outside responsibilities (Bliss \& Sandiford, 2003; Gonzalez, 2010; Espinoza, 2013: Ishitani, 2010). Unfortunately, these struggles get in the way of these students persisting until graduation. According to Bandura, Astin, and Tinto, the students who persist are those who possess the characteristics of self-efficacy for basic college academic skills and utilize self-regulated learning strategies. Study skills is defined as "those activities necessary to organize and complete schoolwork tasks and to prepare for and take tests" (Robbins, Lauver, Le, Davis, \& Langley, 2004, p. 264). Examples of study skills include time management, note-taking, test preparation, and communicating with faculty (Robbins et al., 2004). Though studies have been published regarding the link between academic self-efficacy for basic college academic skills, self-regulated learning strategies, and persistence, there is a gap in the literature regarding the ELL population in that little research has examined these interrelationships among this unique group (Arana, Castañeda-Sound, Blanchard, \& 
Aguilar, 2011; Chung, Marin, \& Pham, 2016; Treviño \& DeFreitas, 2014). Further, the methodology used in previous studies tended to employ quantitative approaches. Most of these studies utilized surveys to obtain their data, but relatively few studies have taken a qualitative approach, such as interviews and observations, which can provide a much more detailed perspective on the meaning of their shared experiences and the accommodations needed for these individuals to persist in higher education (Arana et. al, 2011; Blanchard \& Aguilar, 2011; Coffman, 2011; Collier \& Morgan, 2008, Garza, Bain, \& Kupencynski, 2014; Nandagopal \& Ericsson, 2012).

By identifying a rationale of their views and behavior, the researcher can recommend strategies and other applications that will produce a more adult learnerfriendly environment on college campuses in the future that can help all students succeed. There is an urgent need for research application to help students be successful through explicit instruction and facilitation of self-regulated learning strategies in the curriculum to providing mechanisms to promote student involvement, faculty-student interaction, peer mentoring, and simplifying college entry procedures (Benard, 2004; Conway, 2010; Espinoza, 2013; Collier \& Morgan, 2008; Tovar, 2015; Vega, 2016; Zalquett, 2006).

\section{Purpose of the Study}

The purpose of this phenomenological study was to understand the role of academic self-efficacy and self-regulated learning strategies as part of the learning process for $1^{\text {st }}$ generation Hispanic English Language learners during their first year at a Hispanic-Serving Institution in their intent to persist. Data collection methods will 
include semi-structured interviews, field notes, and the researcher's bracketed autobiography.

\section{Research Questions Guiding the Study}

The primary research question guiding this study is: What is the meaning of the phenomenon of persistence as it is related to academic self-efficacy for basic college academic tasks and self-regulated learning strategies for first-year ELLs at a community college in South Florida?

Secondary research questions are: How can academic self-efficacy and selfregulated learning strategies be applied to learning and persistence in the college experience of first-generation Hispanic English language learners? How does being selfefficacious and utilizing self-regulated learning strategies enhance the college experience of first-generation English language learners?

\section{Significance of the Study}

This study has theoretical, empirical and practical implications. First, the research will enrich what we already knew about Bandura's (1997), Tinto's (1993) student departure, and Astin's (1985) student involvement theories by examining the theories with an underrepresented group, i.e., ELLS. Empirically speaking, if the themes of academic self-efficacy and self-regulated learning strategies are tied to persistence through the interviews and observations with ELLs, then new qualitative evidence would have emerged where ELL students could benefit from learning goal setting, time management, and other techniques that have been found to be effective in previous research with non-ELLS. 
In addition, in a practical sense, this study may determine which self-regulated learning strategies are most influential on persistence in two-year colleges with an ELL population. The insights obtained will help implement changes in the design of the freshman curriculum for ELLs through the incorporation of learning communities, collaborative learning, peer mentoring, more faculty and student interaction in the classroom setting and on campus, at-risk advisement, and more openness to diversity and collaboration with first-generation students in student organizations.

\section{Delimitations of the Study}

Although it would be ideal to study all ELL students in this study to avoid generalizations, this study will focus on first-year college students who are Hispanic English Language Learners in South Florida.

\section{Limitations of the Study}

As this is a phenomenological study, the results cannot be generalized to college students or even ELLs in other parts of the U.S. because of the relatively small sample size and the uniqueness of the ELL population in this area. These students will be atypical college students because they will be part-time, older, commuter students, precluding making anything but tentative generalizations beyond those participating in this research as well (Gonzalez, 2010; Kenner \& Weinerman, 2011; Vassiliou, 2011). In addition, the group of students being interviewed may or may not represent a comprehensive cross section of the ELL community in South Florida. The recurring themes obtained from the interviews could provide a springboard for further theory building and research on the subject, both qualitative and quantitative. The knowledge 
gleaned from the research and the literature review can demonstrate issues of concern and strategies that have been successful for the ELLs students as they persisted with their studies.

\section{Definitions of Terms}

Academic integration: "The development of a strong affiliation with the college academic environment both in the classroom and outside of class. Includes interactions with faculty, academic staff, and peers but of an academic nature (e.g. peer tutoring, study groups)" (Kraemer, 1997, p. 163).

Academic academic self-efficacy: "Refers to students' confidence in their ability to carry out such academic tasks as preparing for exams and writing term papers" (Zajacova, Lynch, \& Espenshade, p. 679, 2003).

Acculturation: "The exchange of both cultural and psychological adaptations that occur when people from different cultures interact” (Fiebig et al., 2010, p. 851).

Achievement gap: “Occurs when one group of students outperforms another group, and the difference in average scores for the two groups is statistically significant (that is, larger than the margin of error)" (The Condition of Education 2014, p. 224).

Active self-regulation: "Is slow, occurs under the conscious control of the central executive process, requires allocation of central capacity resources, and is inherently sequential" (Iran-Nejad, 1990, p. 573).

Andragogue: Adult educator (Knowles, 1977). 
Associate's degree: A degree granted for the successful completion of a subbaccalaureate program of studies, usually requiring at least 2 years (or equivalent) of fulltime college-level study. This includes degrees granted in a cooperative or work-study program (The Condition of Education 2014, p. 224).

Attrition: Lack of persistence in post-secondary education.

Biculturalism (also ethnogenesis): "The emergence of a "hybrid" culture that mixes heritage and receiving cultural streams" (Schwartz \& Zamboanga, 2008, p. 282).

College A postsecondary school which offers general, or liberal arts education, usually leading to an associate's, bachelor's, master's, doctor's, or first-professional degree. Junior colleges and community colleges are included under this terminology (The Condition of Education 2014, p. 224).

Convergent validity: "is a correspondence or convergence between constructs that are theoretically similar” (DeVon, Block, Moyle-Wright, Ernst, Hayden, Lazzara, Savoy, Kostas-Polston, 2007, p. 155).

Cultural transmission: The "group-level transmission of coping resources and coping strategies" (Gayman et. al., 2014, p. 211).

Dropout intention: "The inclination, conscious and discussed, to leave the university or to end one's studies (Bean, 1985).

Dynamic self-regulation: "Is rapid, occurs under the spontaneous control of the nonexecutive components of the nervous system, uses resources available locally in the 
nonexecutive components themselves, and is inherently simultaneous" (Iran-Nejad, 1990, p. 573).

English for Academic Purposes (EAP): ESOL classes designed specifically for degreeseeking students.

Educational attainment: The highest grade of regular school attended and completed (The Condition of Education 2014, p. 226).

English language learner (ELL): An individual who, due to any of the reasons listed below, has sufficient difficulty speaking, reading, writing, or understanding the English language to be denied the opportunity to learn successfully in classrooms where the language of instruction is English or to participate fully in the larger U.S. society. Such an individual (1) was not born in the United States or has a native language other than English; (2) comes from environments where a language other than English is dominant; or (3) is an American Indian or Alaska Native and comes from environments where a language other than English has had a significant impact on the individual's level of English language proficiency (The Condition of Education, p. 226-227).

Evidence-based practice: "Involves a decision-making process which includes practitioners' competent delivery of interventions that are grounded in vigorous research" (Rahill, Jean-Gilles, Thomlinson, \& Pinto-Lopez, 2011, p. 135)

Evidence-informed practice: "Describes a way of practicing in which the practitioner critically uses best evidence. expertise, and values to make practice decisions that matter 
to individual service recipients" (Rahill, Jean-Gilles, Thomlinson, \& Pinto-Lopez, 2011, p. 136)

Ethnography: "The description and interpretation of a cultural or social group system" (Creswell, 1998, p. 58).

External locus of control: The perception one has no control over outcomes because they are determined by nonbehavioral factors (Azjen, 2002).

Financial aid: Grants, loans, assistantships, scholarships, fellowships, tuition waivers, tuition discounts, veteran's benefits, employer aid (tuition reimbursement), and other monies (other than from relatives or friends) provided to students to help them meet expenses. Except where designated, includes Title IV subsidized and unsubsidized loans made directly to students (The Condition of Education 2014, p. 227).

First-generation college students: "Students whose parents never attended college" (Ishitani, 2006, p. 862).

First-generation immigrants: "Foreign-born" people (Baum \& Flores, 2011, p. 173).

Generality of self-efficacy: It "pertains to the transferability of self-efficacy beliefs across activities" (Zimmerman, 2000, p. 83).

Higher education institutions (basic classification): 4-year institution An institution legally authorized to offer and offering at least a 4-year program of college level studies wholly or principally creditable toward a baccalaureate degree. In some tables, a further division between universities and other 4-year institutions is made. A "university" is a postsecondary institution which typically comprises one or more graduate professional 
schools. For purposes of trend comparisons in this volume, the selection of universities has been held constant for all tabulations after 1982. "Other 4-year institutions" would include the rest of the nonuniversity 4-year institutions.

Hispanic or Latino: A person of Cuban, Mexican, Puerto Rican, South or Central American, or other Spanish culture or origin, regardless of race. Used interchangeably with the shortened term Hispanic ( Humes, Jones, \& Ramirez, 2011, p. 2).

Hispanic-serving Institutions (HSIs): "2-or 4-year, not for profit colleges and universities that enroll at least 25\% Hispanic students" (Santiago, 2006, p. ).

Implementation intention: If-then plans created for the purpose of reaching a goal. (Gollwitzer, 1993, 1999). "Such plans create a strong link between a critical cue (e.g. "When I get out of bed in the morning...") and a goal-directed behavior (e.g.,".., then I will put on my running shoes!") by one single, conscious act of will (Bayer et. al., 2010, p. 506).

Information acquisition strategies: "Repetition and attentional strategies." (Muelas \& Navarro, 2014, p. 218).

Information coding strategies: "Mnemonic organizational and development strategies." (Muelas \& Navarro, 2014, p. 218).

Information retrieval strategies: "Search strategies and response generation." (Muelas \& Navarro, 2014, p. 218).

Internal locus of control: The perception that one has behavioral control over outcomes (Ajzen, 2002). 
Less-than-2-year institution: An institution that offers programs of less than 2 years' duration below the baccalaureate level. Includes occupational and vocational schools with programs that do not exceed 1,800 contact hours.

Level of self-efficacy: "Refers to its dependence on the difficulty of a particular task" (Zimmerman, 2000, p. 83).

Locus of control scales: "Refer to general beliefs about the internality or externality of causality" (Zimmerman, 2000, p. 85).

Metacognition: “The knowledge about and regulation of one's cognitive activities in learning processes (Flavell, 1979; Brown, 1978) found in Veenman et.al.

Natives: "Third generation or higher-include individuals who were born in the United States and both of whose parents were born in the United States" (Baum \& Flores, p. 173, 2011).

Nontraditional students: "Defined as students who are older, attend school part-time, and are financially independent” (NCES, 2002b) (Zajacova, Lynch, and Espenshade, 2003). Part-time enrollment: The number of students enrolled in higher education courses with a total credit load less than 75 percent of the normal full-time credit load. At the undergraduate level, part-time enrollment includes students who have a credit load of less than 12 semester or quarter credits. At the post-baccalaureate level, full-time enrollment includes students who have a credit load of less than 9 semester or quarter credits (p. 230). 
Perceived control: "Refers to general expectancies about whether outcomes are controlled by one's behavior or by external forces" (Zimmerman, 2000, p. 85).

Perceived self-efficacy: "Personal judgments of one's capabilities to organize and execute courses of action to attain designated goals" (Bandura, 1977a; Bandura 1997).

Persistence: A student who remains in college until graduation.

Postsecondary education: Formal academic, vocational, and continuing professional instructional programs with a curriculum designed primarily for students who have completed the requirements for a high school diploma or equivalent.

Poverty: The U.S. Census Bureau uses a set of money income thresholds that vary by family size and composition. A family, along with each individual in it, is considered poor if the family's total income is less than that family's threshold. The poverty thresholds do not vary geographically and are adjusted annually for inflation using the Consumer Price Index. The official poverty definition counts money income before taxes and does not include capital gains and noncash benefits (such as public housing, Medicaid, and food stamps). (p. 230).

Processing support strategies: "Metacognitive and socioaffective strategies" (Muelas \& Navarro, 2014, p. 218).

Resiliency: The ability to succeed by overcoming obstacles and difficult situations (Gordon, 1996) 
Reverse Acculturation: "Refers to the cultural practice wherein a fully acculturated U.S. born minority member introduces the heritage culture to the U.S. society" (Kim \& Park, 2009, p. 359).

Second-generation immigrants: "Were born in the United States and have at least one foreign-born parent" (Baum \& Flores, 2011, p. 173).

Self-efficacy: The belief that one can do what one has set out to do (Bandura, 1997).

Self-regulated learning strategies: Processes that utilize self-observation, self-judgment, and self-reactions (Zimmerman, 1989).

Social integration: The development of a strong affiliation with the college social environment both in the classroom and outside of class. Includes interactions with faculty, academic staff, and peers but of a social nature (e.g., peer group interactions, informal contact with faculty, involvement in organizations)" (Kraemer, 1997, p. 163).

Socioeconomic status: A combination of family income, occupation, and education (White, 1982).

Social self-efficacy: The belief that one can do what one has set out to do to communicate well with others (Bandura, 1997).

Strength of perceived efficacy: "Measured by the amount of one's certainty about performing a given task" (Zimmerman, 2000, p. 83).

Stress: a state of psychological arousal that results when external demands tax or exceed a person's adaptive abilities (Zacova, Lynch, \& Espenshade, p. 678, 2003). 
Stress buffering: "When the negative impact of stress exposure on health is weakened at higher levels of coping resources and/or is magnified at low levels of coping resources" (Aneshensel, 2009) (Gayman et. al., 2013, p. 198).

Stress process model: "Exposure to chronic stress has negative health consequences and the coping resources buffer negative health outcomes associated with social stressors" (Gayman, Cislo, Goidel, \& Ueno, 2013, p. 198).

Tacit theory: The lack of awareness that one possesses a theory regarding one's learning process (McCutcheon, 1992).

Test of English as a Foreign Language (TOEFL): Assessment used at the post-secondary level to exit ELLs from the ESOL program.

Transculturation: "The newcomer immigrants and the Americans are changing, adapting to each

other." (Stepick, Grenier, Castro, and Dunn, 2003, p. 144).

Tuition and fees: A payment or charge for instruction or compensation for services, privileges, or the use of equipment, books, or other goods. Tuition may be charged per term, per course, or per credit (p. 232).

Two-year institution: An institution legally authorized to offer and offering at least a 2year program of college level studies which terminates in an associate degree or is principally creditable toward a baccalaureate degree. Also includes some institutions that have a less than 2-year program but were designated as institutions of higher education in the Higher Education General Information Survey 
Undergraduate students: Students registered at an institution of higher education who are working in a baccalaureate degree program or other formal program below the baccalaureate, such as an associate's degree, vocational, or technical program. (p. 232).

\section{Organization of this Study}

This study is organized into five chapters. In the first chapter, the background for the topic of persistence in English language learners in college was introduced, along with the problem statement, and the purpose of this study. The characteristics and struggles of Hispanic first-generation students were followed by the theories of Bandura, Astin, Tinto, Zimmerman, and Knowles. The significance of the research, the delimitations and limitations of this study, and the definition of terms are included in this chapter as well.

For the second chapter, a review of the literature was conducted to examine in greater depth the topics which were first introduced in chapter one. Studies that were both qualitative and quantitative in nature and related to persistence, andragogy, Bandura and the above-mentioned educational researchers, in addition to Hispanic first-generation college students were discussed.

The third chapter consisted of the phenomenological framework utilized in this study. The researcher included her autobiography and assumptions made regarding the study. The procedures used for sampling criteria, data collection, data analysis, data management, and integrity measures were reviewed. For the fourth chapter, the findings and the themes that emerged from the study were discussed. The fifth chapter examined the implications and the recommendations for future research. 


\section{CHAPTER II}

\section{REVIEW OF THE LITERATURE}

This chapter will review the literature on Hispanic college students who are learning English as a second language, and how their culture, background, and socioeconomic status helps and challenges them in the world of higher education. In addition, the attributes of academic self-efficacy and self-regulated learning strategies and the roles they play in persistence to graduation will be explored to determine what links have been observed in previous studies, especially regarding English language learners. The history of academic self-efficacy and self-regulated learning strategies and their relationship to persistence is found in Bandura's social cognitive theory, Tinto's theory of student departure, and Astin's theory of student involvement. This chapter is comprised of eight sections: Hispanic ELLs' Characteristics, Hispanic ELLs' Obstacles to Persistence, Self-Efficacy and Self-Regulated Learning Strategies and their Relationship to Persistence, Bandura's Social Cognitive Theory, Tinto's Theory of Student Departure, Astin's Theory of Involvement, Application to Higher Education, and Summary.

\section{Hispanic ELL's Characteristics}

This research study is primarily focusing on the Hispanic ELL population in Southwest Florida, who share many, but not all characteristics in common with Hispanics in other parts of the United States. Most of the Hispanic students in this area are firstgeneration immigrants, as well as first-generation college students, who speak Spanish as their first language. First-generation immigrants are defined as being foreign-born, 
second-generation immigrants are those that were born in the United States, but have at least one non-native parent, and natives are those who were born in the United States and whose parents were both born in the United States as well (Baum \& Flores, 2011). However, an individual may be a native of the United States, yet still be considered a first-generation college student because he or she is the first one in the family to attend college (Ishitani, 2006). Although the percentage of Hispanics in higher education has increased (Arana et al., 2011), only 9\% of first-generation Hispanics have earned a Bachelor's degree compared to $54 \%$ for whites, $63 \%$ for Asians, and $30 \%$ for blacks who are also first-generation immigrants (Baum \& Flores, 2011).

Parental achievement, academic preparation, and age at immigration are also significant factors that determine the likelihood of ELLs' academic achievement. Studies have shown that Hispanics whose parents had not attended college and/or immigrated when they were older than thirteen were much less likely to attend college themselves (Barbatis, 2010; Baum \& Flores, 2011; Kim et. al., 2015). The parents of these English language learners often had two or more jobs to make ends meet, and had difficulty communicating with their children's teachers due to time constraints and the language barrier (De La Cruz, 2008). In addition, many first-generation college students find that they must learn to navigate the college application process by themselves and visit the school's counselor's office to obtain updates on college entrance exams such as the SAT and ACT, financial aid and scholarship information, etc. (Crisp \& Nora, 2009; Treviño \& De Freitas, 2014; Zalaquett, 2005). 
Hispanic ELLs whose parents had graduated from high school and attended college were much more likely to graduate from high school and continue with higher education, especially if their mothers were the ones who had attended college (Kim et. al., 2015). Another positive influence in the lives of Hispanic ELLs are teachers and professors who serve as mentors for these young people and provide encouragement and support (Barbatis, 2010; De La Cruz, 2008; Kim et. al., 2015; Reyes \& Garcia, 2013).

Of those Hispanic ELLs who do decide to pursue higher education, most of them find that it is best to attend a community college for various reasons: they have an opendoor policy on admissions, are more affordable than universities, and offer remedial and EAP (English for Academic Purposes) courses (Liao, Edlin, \& Ferdenzi, 2014). Moreover, more non-traditional students enroll in community colleges because they are smaller and located closer to home so that older students with familial obligations can work full-time and attend school part-time (Bliss \& Sandiford, 2003; Hu \& Driscoll, 2012). While community college students benefit from the convenience and open-door policy of these institutions, many of them begin their college experience underprepared for this undertaking (Hu \& Driscoll, 2012). They may also suffer from a disconnect from the college experience due to the short duration of time they spend on campus, as compared to their peers at the universities who tend to become more involved in college life (Bliss \& Sandiford, 2003).

Much of the literature in this study describes Hispanic communities in California, Texas, and New York, and these populations differ in some ways from the Hispanic population in South Florida, namely Miami (Arana et. al, 2011; Gonzalez, Stein, \& Huq, 
2012). In the southwestern United States, for example, there is a large Mexican-American community, whereas in Miami, the preponderance of Hispanics originates in Cuba, along with Colombians, Nicaraguans, Dominicans, Peruvians, and Puerto Ricans (Bliss \& Sandiford, 2003; Zalaquett, 2005). The Hispanic population in other parts of the United States has a greater population of second-generation immigrants who have had to learn the English language and adapt to mainstream culture (Gonzalez, Stein, \& Huq, 2012; U.S. Census Bureau 2010). The Hispanic community in Miami is newer compared to many of these older communities. Due to its geographical location as one of the southernmost cities in the continental United States, Miami has become the northernmost city of Latin America (Schwartz, Benet-Martinez, Knight, Unger, Zamboanga, Des Rosiers, Stephens, Huang, Szapoczanik, 2014). In addition, the Hispanic community living in Miami tends to be more politically conservative than other Hispanic communities in the U.S., despite suffering many of the same hardships. A minority of Hispanic ELLs who move to Miami are surprised to discover that they are being asked to adapt to a predominantly Hispanic community which is well-established and mostly bilingual, instead of mainstream American culture. This fact attracts a large group of Hispanics to Miami because they feel that it will be much easier to adapt to their new country, especially because the subtropical climate is also reminiscent of their homelands (Schwartz et. al, 2014). In Miami, some of the Hispanics feel comfortable with the mainstream White culture, while others identify with both cultures, and others only embrace their native cultures (Barbatis, 2010; Gonzalez, 2010; Schwartz \& Zamboanga, 2008). Studies have demonstrated that Hispanics' level of support by their peers and 
families will depend on their level of acculturation and socioeconomic status (Gayman et al., 2013).

However, it must be noted that the acculturation experience undergoes a unique transformation in Miami, Florida. One acculturation theory, Berry's Model of Acculturation consists of four attitudes: assimilation, integration, separation, and marginalization. Assimilation describes the individuals as being willing to adapt to the mainstream culture, while shedding aspects of their own culture. With integration, the individual or group wants to blend characteristics of both cultures. Separation means that the person wants to maintain his or her cultural identity without interference from the mainstream culture. Finally, individuals who choose marginalization want nothing to do with any culture at all (Berry, 2006)

Rather than follow the steps delineated in Berry's Acculturation Model, biculturalism or ethnogenesis, which is considered the birth of a mixed-heritage "hybrid culture" Schwartz \& Zamboanga, p. 281, 2008), is greatly encouraged in Miami. Therefore, the acculturation process as described by Berry's Model of Acculturation in Miami favors biculturalism or integration to a significant extent, although the other attitudes are present as well.

In addition, Hispanic cultures, though they have many characteristics in common, particularly the language, differ in some ways. The Hispanic culture in Miami is represented by more countries than other cities in the United States. Miami, where this research study takes place, is predominantly a blend of Caribbean, Central, and South American countries (Bliss \& Sandiford, 2003; Gonzalez, 2010). Additionally, Stepick, 
Grenier, Castro, and Dunn (2003) came across an interesting phenomenon in their Miami research study: that of reverse acculturation, which is described as Whites adopting the Miami Cuban and Latino culture and learning the Spanish language, but they felt that it was not just limited to reverse acculturation. "Transculturation, in which the newcomer immigrants and the Americans are changing, adapting to each other" (p. 144) is occurring simultaneously as well. Transculturation is similar to Berry's integration, because both of these terms address the exchange between cultures. The study conducted by Gonzalez found that three main themes played recurring roles in his research: typical food and its role in celebrations, how the degree of cultural appreciation affected conflict in families, and how language was utilized (English only, Spanglish, bilingual) (2010). The implication of this study was that an institution should not make assumptions regarding students' ethnic identities, and allow students to identify themselves (Gonzalez, 2010).

\section{Hispanic ELLs' Obstacles to Persistence}

Hispanic ELLs immigrate from their countries for varying reasons, such as finances, better opportunities, and fleeing government repression (Zalaquett, 2005). Although many Hispanics enter college at higher rates than other ethnicities, researchers have found that there is a low level of persistence whether it be at a two-year or four-year institution (Bliss \& Sandiford, 2003; Tovar, 2014). First-generation immigrants are willing to work hard to improve their socioeconomic status and provide for their families. Many of them also hope to provide their children with the opportunities they never had and facilitate the way to higher education (Arana et al., 2011). Parental support was also viewed as encouraging persistence (Arana et al., 2011; Fiebig et al., 2010). Before many 
Hispanic ELLs can think of their educational goals, they need to solve more pressing issues such as taking care of their immigration status, securing employment, and finding a place to live (Baum \& Flores, 2011; Gayman, Cislo, Goidel, \& Ueno, 2013; Muelas \& Navarro, 2015). For instance, undocumented students must pay out-of-state tuition rates that are exorbitantly higher than in-state tuition rates (Baum \& Flores, 2011; Siemons, Ramond-Flesh, Auerswald, \& Brindis, 2017). The process of securing employment without a work permit or command of the English language can further hinder the pursuit of post-secondary education, along with the search for an affordable place to live, which has become increasingly more difficult in Miami-Dade County (Siemons, et. al, 2017).

Even supposing those students overcome those hurdles, to be successful in the college environment, it is necessary to assimilate into the mainstream culture, and commit to persisting (Arana et. al., 2011; Muelas \& Navarro, 2015; Nakajima, Dembo \& Mossler, 2012). According to Fiebig, Braid, Ross, Tom, and Prinzo, first and secondgeneration Hispanics, particularly women, experience less acculturation than their third or fourth generation peers (2010). Many Hispanic ELLs feel like outsiders in college and are afraid that they will be perceived as foreign (Muelas \& Navarro, 2015). This perception has such an impact, that the more Hispanic ELLs believe that there is a disparity between their culture and the institution they are attending, the less likely they are to persist (Arana et. al., 2011). An increasing number of Hispanic ELLs enroll in 2year Hispanic-Serving Institutions or (HSIs) because they are closer to home, and they feel more comfortable attending an institution with a greater number of students from similar backgrounds (Arana et al., 2011; Nuñez \& Bowers, 2011). One of the implications of these findings is that the institution should attempt to create a familial, 
supportive atmosphere as well as create intervention programs (Almon, 2015; Fiebig et al., 2010; Gayman et al., 2014).

Lack of English proficiency is one of the main reasons that Hispanic ELLs feel like outsiders in higher education (Baum \& Flores, 2011; Nakajima, Dembo, \& Mossler, 2012). Background variables such as gender, age, socioeconomic status, numbers of hours worked, and financial aid also figured prominently as factors, with high school and freshman GPA being directly associated with persistence (Baum \& Flores, 2011; Nakajima, Dembo, \& Mossler, 2012). In fact, students whose parents have not attended college are much more likely to not attend college or persist, especially because their parents cannot assist them with the college application process (Almon, 2015; Baum \& Flores, 2011; Fieberg et al., 2010). They will also demand more from themselves and have planned for their careers (Fiebig et al., 2010).

First-generation students tend to not seek support from their families, peers, or faculty members (Fiebig et al., 2010). However, academic integration is considered crucial to students' success and persistence (Fiebig et al., 2010). Interaction with faculty members outside of the classroom setting is extremely influential in student persistence, but is not as common in community colleges due to the part-time status of adjunct professors (Barbatis, 2010; Tovar, 2014). Because the transition from secondary to postsecondary student can be stressful, it is important to be aware of the stress-process model or the stress-buffering hypothesis. This model is based on the belief that chronic stress can negatively affect health and the individual should possess "coping resources" as a "buffer" for these stress-induced illnesses (Gayman et al., 2014, p. 198). The 
researchers found that the disparity among ethnic groups' differing coping mechanisms were due to culture, and not to socioeconomic status. A quantitative study conducted several years ago indicated that non-Hispanic Whites possess more social coping mechanisms or stress buffering, whereas African-Americans possess more self-esteem when compared to Cubans and Nicaraguans in Miami (Gayman et al. 2014). Another study found that immigrant Hispanics or first-generation Hispanics had more parental support than those young adults who had at least one parent born in the U.S. (Moilanen \& Raffaelli, 2010). Despite this parental support, first-generation college students need to navigate the world of higher education, which includes everything from applying to financial aid to organizing their study time effectively. Unfortunately, their parents cannot assist them in this regard, in contrast to the parents who are college graduates, and are recipients of cultural transmission as pertains to higher education (Espinoza, 2013). Cultural transmission is defined as the "group-level transmission of coping resources and coping strategies" (Gayman et al., 2014, p. 211). It is believed that this cultural advantage is passed down from generation to generation, and greatly facilitates how individuals experience college and the real world after high school (Gayman et al., 2014). Therefore, first-generation college students can be very adept at survival skills, but struggle when it pertains to succeeding in higher education (Espinoza, 2013; Ishitani, 2006, Treviño \& De Freitas, 2014).

Additionally, with nonpersisters, or students who did not graduate, researchers found that having full-time employment was detrimental to persistence (Arana et. al., 2011; Nakajima, Dembo, \& Mossler, 2012). Furthermore, the responsibility of supporting minor dependents and elderly family members increased the probability of dropping out 
(Baum, \& Flores, 2011; Nakajima, Dembo, \& Mossler, 2012). Students who did not persist also tended to identify more with their cultures than students who did persist (Barbatis, 2010). Finally, legal barriers, academic institutions, and communities in which students reside also play a role in persistence (Baum \& Flores, 2011). In Almon's qualitative study, recurring barriers cited by the subjects were finances, full-time employment, and familial obligations. Some students qualified for financial aid, and some did not, so that was a persistent source of anxiety every semester. Many students found it difficult to find the time and energy to study and spend time with family (2015). Despite all the obstacles, researchers have found that first-generation students are more likely to enroll in college than third-generation students or native Hispanic students (Baum \& Flores, 2011).

Moreover, most Hispanic ELLs attend college part-time, but full-time students consistently earn higher grades and are more likely to persist than part-time students $(\mathrm{Hu}$ \& Driscoll, 2013; Kenner \& Weinerman, 2011). These part-time students fall under the classification of nontraditional students, or students "who are older, attend school parttime, and are financially independent” (NCES, 2002b) (Zajacova, Lynch, and Espenshade, 2003).

\section{Self-Efficacy, Self-Regulated Learning Strategies and Persistence}

It is important to distinguish between generalized self-efficacy and academic selfefficacy because little to no relationship has been found between generalized self-efficacy and academic success, whereas research on academic self-efficacy has "consistently 
shown to predict grades and persistence in college" (Zajacova, Lynch, \& Espenshade, p. $679 ; 2003)$.

Most researchers have determined that even though adult college students experience stress, academic self-efficacy was a more consistent predictor of academic success than stress. For example, Torres and Solberg (2001) determined that Hispanic students' persistence was more correlated with academic self-efficacy than stress. However, academic stress, or college-related stress, is detrimental to the persistence of all students, but especially nontraditional students or students with nontraditional characteristics. When dealing with acculturative stress, or stress pertaining to the process of getting used to a new culture, nontraditional and minority students are more "predisposed" than native-born White students. This is especially true for new immigrants (Zajacova et al., p. 680; 2003).

According to McCoy (2010), academic self-efficacy is increased when students have access to a computer at home; this is especially true for the 25 -and-over population. She suggests that providing students who cannot afford computers with laptop computers is an excellent way of ensuring proficiency in technology and self-efficacy because students can become more technologically savvy as well as enhance their learning through technological resources.

The decision to implement goals, or implementation intentions as a tool can make all the difference with goal achievement. To reach the desired outcome, the time, place, and circumstances for implementation must be specified (Bayer et. al., 2010; Gollwitzer, 1993, 1999). After a certain period, the behavior becomes automatic, or "hypo-egoic 
self-regulation," because the subconscious mind automatizes behavior, so it does not require for that the individual make a conscious effort to behave as intended (Bayer et al., 2010; Leary, Adams, \& Tate, 2006). Hypo-egoic behavior is defined as the state in which "people relinquish deliberate conscious action control so that they are able to respond more naturally, spontaneously, or automatically" (Bayer et. al., 2010, p. 513). At first glance, it seems like this automatic behavior is synonymous with a habit, but the distinction between the two is the deliberate pairing of the stimulus and the behavior (Aizen, Czasch, \& Flood, 2009).

Nandagopal and Ericsson's (2012) study found that students utilized selfregulated learning strategies, such as organizing and reviewing their notes more frequently at specific times during the semester, such as midterm week. Students in the study with higher GPAs possessed certain characteristics in common because they employed self-regulated learning strategies more consistently as compared to those with lower GPAs. They also sought the help of their peers earlier on during the semester than low-achieving students who did so towards the end of the semester. "More informative and predictive" strategies were studied on an individual basis instead of grouping them into categories (p. 605). However, these researchers acknowledged that the population in their study consisted of upper-level science majors who were probably high achievers in high school because this applied to even the low achievers in the study (Nandagopal \& Ericsson, 2012).

According to research by Muelas and Navarro (2014), learning strategies such as information coding and information recovery play an important role in academic 
performance. Beltran proposed that the strategies should be classified into three categories: support strategies, processing, and knowledge strategies. Further, Hu and Driscoll (2013) demonstrated that an intervention consisting of self-regulatory strategies on computer-based learning could positively impact both academic achievement and persistence. Similarly, a computer-based software program called A + dvancer College Readiness Online helped facilitate progress when Miami-Dade College students in need of remediation utilized it (Vassiliou, 2011).

There are other factors besides self-regulation which improve the odds of persisting. For example, socioeconomic status, rigorous college preparatory courses in high school, and the option to attend an alternative to community colleges such as state universities, research universities, and private colleges have been found to significantly favor persistence (Carter, 2006; Nakajima, Dembo, \& Mossler, 2012). Two-year colleges have a problem with retention as well as attrition, especially when compared to four-year institutions (Nakajima, Dembo, \& Mossler, 2012). However, researchers have shown that community college students with "educational objectives" are more likely to succeed and persist (Nakajima et al., p. 593, 2012).

Socioeconomic status is positively correlated with achievement because the students are less likely to have to preoccupy themselves with paying for college; they tend to obtain assistance from their parents in the college application process. In addition, students who belong to a higher socioeconomic status are often encouraged to take honors or Advanced Placement (AP) courses because they prepare students for college coursework and equip students to do well on the SAT (Scholastic Achievement Test; 
Carter, 2006). As a result, they can attend a university or private college that promotes persistence as compared to two-year colleges because of the greater faculty-student interaction and student events found in these institutions (Carter, 2006; Chang, 2005; Tinto, 1982).

\section{Bandura's Social Cognitive Theory}

Bandura's social cognitive theory demonstrates how academic self-efficacy, outcome expectations, goals, and sociostructural factors play a role in influencing and predicting behavior (Bandura, 2012). Self-efficacy is defined as "the personal judgments of one's capabilities to organize and execute courses of action to attain designated goals (Bandura, 1997, p. 37). This type of efficacy is perceived self-efficacy because it is what the individual perceives about himself or herself. According to Bandura, many different types of self-efficacy exist; the one that is pertinent to this research is academic selfefficacy, which concerns itself with how students believe they will perform in a class or a test, for example. Students with high academic self-efficacy tend to perform better than with low academic self-efficacy because they are more motivated to take on and persist in challenging tasks, while employing effective self-related learning strategies to do so. The students' efficacious beliefs related to academic tasks and confidence in their ability to perform such tasks comes about in four ways, as a result of: (1) positive mastery experiences related to performing the task, (2) vicarious experiences (observation of others successfully performing the task), (3) verbal and social persuasion (encouragement from parents, teachers and peers can boost confidence), and (4) emotional and physiological state (strong emotional reactions to school-related tasks can provide a hint 
to expected success or failure; high anxiety and stress can dampen academic selfefficacy). Hispanics and other minorities tend to demonstrate lower academic selfefficacy because they tend not to have the multitude of positive mastery learning, vicarious, verbal and social persuasion, and emotional experiences, as compared to those in the majority culture, required to build academic efficaciousness levels (Bandura, 1997).

Bandura (1997) believes that people influence themselves, others to act for them, and collectively as a group to shape their circumstances. He calls this the agentic perspective (Bandura, 2002). "To be an agent is to influence intentionally one's functioning and life circumstances" (Bandura, 2002, p. 270). The notion of "agentic perspective" plays a significant role in determining success because the belief system and skills are directly related to the behavior. However, Bandura (2001) believes that there is a "triadic relationship" between personal, behavioral, and environmental determinants, which means that they all influence each other to determine behavior.

When students utilize self-regulating learning strategies to gain mastery (the most powerful source of self-efficacy) of a specific topic and thus increase their level of efficaciousness, it signifies that they employ techniques that will facilitate the learning process in some way, whether it be using tutorials, time management skills, and monitoring (Bandura, 1997). Of course, for self-regulation strategies to work, the teacher or the student needs to be aware of the schemata, or background knowledge the student possesses. Without this knowledge, it is difficult to achieve mastery because there is no 
sense of direction. Mastery of a subject depends on a correct evaluation of a person's skills so that progress can be made (Bandura, 1997).

\section{Tinto's Theory of Student Departure}

Tinto's work on persistence emphasizes that students' precollegiate family and academic backgrounds influence persistence more heavily than the period where students are already enrolled in institutions of higher learning. Tinto identifies "ethnicity, level of family support, socioeconomic status, and secondary school achievement as primary characteristics" (Barbatis, 2010. p. 18). Tinto identifies three stages as contributing to persistence: separation, transition, and incorporation. He insists that these stages must take place so that students assimilate into the college environment and remain until graduation (Barbatis, 2010; Tinto, 1988). In Tinto's student departure model, the stage of separation is characterized by the students leaving the academic, social, and family communities they have become accustomed to for many years or even from birth. For the traditional students, this entails leaving their families, neighborhoods, and high school friends. However, Tinto explains that with regards to commuter students who stay at home, this stage might be easier in some ways and more difficult in others because the students do not have to leave the familiarity of their home environments, but they cannot benefit from incorporating themselves into the college community, which can be detrimental to persistence.

The second stage is the transition stage in which the students adapt to their new environment. Students who attend traditional four-year colleges need to undergo the acculturation process to adapt to their new lifestyle. However, if the institution is a non- 
residential two-year college, complete integration is not essential, but it would diminish the availability of student-faculty interaction, especially because most faculty members are adjunct or part-time professors (Tinto, 1988).

The third stage is incorporation into college, which means that the students integrate into the college's community. At this point, the students must internalize the new rules and customs of their new environment and socialize with students and faculty members because their persistence in the institution depends on it. The alternative to this would be isolation and the negative repercussions associated with this. The students, like Hispanic ELLs, who attend commuter colleges or who live at home do not have to adapt per se, but they may find it difficult to remain focused on their goal to persist, especially if they are not supported by friends and family members (Tinto, 1988).

\section{Astin's Theory of Student Involvement}

Being socially involved in the college experience while maintaining cultural ties has benefitted many minority students (Barbatis, 2010). In traditional students, Pascarella and Terenzini (1979) found that "lack of integration into the college environment, due to insufficient contact with members of the institution, as perhaps the most important predictor of student withdrawal" (Kraemer, 1997, p. 163). However, the bulk of Hispanic ELLs tend to be part-time commuter students. The results of Kraemer's study demonstrated that for commuter students, academic integration was more influential on persistence than social integration, regardless of whether it was a two-year or four-year institution (Chang, 2005; Kraemer, 1997). According to Chang (2005), there is a lack of research studies on faculty involvement in two-year institutions. The research 
demonstrates that as far as student club participation is concerned, that students overwhelmingly participate more in four-year institutions versus the two-year institutions.

\section{Application to Higher Education}

Underprepared college students like ELLS often must take remedial or developmental courses before they begin their major requirements. Some researchers believe that these courses should not be taken in isolation, but as part of their regular coursework to demonstrate that there is a relationship among disciplines and make sure they also begin to earn college credits (Barbatis, 2010).

Although not a primary focus of this research, it may be useful for college professors to be knowledgeable about adult education methods to facilitate optimal learning among ELLS (Knowles, 1990; Knowles, Holton, \& Swanson, 1998; Wang \& Hansman, 2016). Many adjunct professors teach full-time in the K-12 educational system, and do not adjust their instructional methodologies to reflect the adult, nontraditional student population like ELLS (Barbatis, 2010: Knowles, 1990). College professors should devise methods to help ELLS develop a stronger self-concept about themselves as learners, which can be gained through designing mastery learning experiences to increase their competence and confidence as able, self-efficacious learners. Knowles also believed that self-directedness is what the andragogue, or adult educator should be striving for, whereas it is not a main goal of the pedagogue, or child educator. In fact, Knowles thinks that it is the andragogue's obligation to assist the adult, nontraditional learner to move from dependency to self-reliance (Knowles, 1990), which 
means professors gradually transferring the responsibility and control of the students' learning from the professors to the students. Other educational researchers such as Rogers and Tennant also agree that adult educators should be facilitators who are genuine, understanding, and accepting of their students (Wang \& Hansman, 2016). Selfdirectedness is a form of self-regulation and thus should be embraced as a learning strategy to promote optimal ELL learning (Bandura, 1997).

In addition, honoring adults' experiences in the classroom is in alignment with Knowles's (1977) andragogical principles; that is, nontraditional ELLs or ELLs with nontraditional characteristics should be able to draw upon their own experiences to enhance their learning. Adult learners learn best when they can draw upon their personal experiences to make sense of and internalize academic learning. Further, the motivation to learn differs between children and adults. Adult learners, for the most part, tend to be more intrinsically than extrinsically motivated than children (Knowles, 1998). Whether they are enrolled in higher education because of their curiosity and love of learning, the need to improve their financial situation, or both, adult ELLs know why they are learning something new (Knowles, 1998; Tight, 2002). Thus, learning endeavors should begin with informing the ELLs why they need to learn a topic area by linking it to an important goal like a career or attaining their college degree.

Overall, if the adult, nontraditional ELLs or ELLS with nontraditional characteristics hope to persist in the challenging environment of college classrooms, they may need to be more academically self-efficacious and use more self-regulated learning strategies to become academically successful. Adult educators need to realize that despite 
generalizations made by Knowles and other education theorists, that individual differences and backgrounds play a significant role in learning styles, self-directedness, and motivation (Caffarella \& Merriam, 2000; Tight, 2002). Professors who utilize Knowles' andragogical assumptions while keeping in mind that adult learners are individuals who have been molded by their own personal experiences with gender, race, ethnicity, and oppression can facilitate learning for the growing number of nontraditional learners (Caffarella \& Merriam, 2000).

\section{Summary}

In this chapter, the characteristics of Hispanic College English Language Learners was discussed, along with the obstacles they face to achieve academically and persist until graduation. Bandura's (1997) social cognitive theory, Tinto's (1993) theory of student departure, Astin's (1985) theory of involvement, and Knowles's (1968) theory of andragogy provided a theoretical perspective on the variables involved in higher education as pertains to academic achievement, persistence, and the roles that the community play in this regard. The ways in which the findings can be applied to higher education are also discussed. Chapter three will explain why the phenomenological approach is best suited for the purposes of this study and gaining a richer insight with more detailed clarification. Upon approval of this proposal, chapters four and five will describe the results and the implications derived from the research. 


\section{CHAPTER III}

\section{METHOD}

The purpose of this phenomenological study was to understand the role of academic self-efficacy and self-regulated learning strategies as a learning process for $1^{\text {st }}$ generation Hispanic English Language learners during their first year at a HispanicServing Institution in their intent to persist.

\section{Research Questions Guiding the Study}

The primary research question guiding this study is: What is the meaning of the phenomenon of persistence as it is related to academic self-efficacy for basic college academic tasks and self-regulated learning strategies for first-year ELLs at a community college in South Florida?

Secondary research questions are: How can academic self-efficacy and selfregulated learning strategies be applied to learning and persistence in the college experience of first-generation Hispanic English language learners? How does being selfefficacious and utilizing self-regulated learning strategies enhance the college experience of first-generation English language learners?

\section{Phenomenological Framework}

The phenomenological approach is defined as "a strategy of inquiry in which the researcher identifies the essence of human experiences about a phenomenon as described by participants" (Creswell, 2009, p.13). According to Adams and Van Manen (2017), 
phenomenology is concerned with "experience as lived, that is, as it is, was or may have been experienced in the lived moment" (p. 782). This approach is characterized by a researcher who attempts to be as objective as possible and who chooses to study a small sample of participants with the purpose of engaging with them in depth. The researcher then reviews the description of their experiences to determine what if any are the recurring themes (Creswell, 2009). According to Bogdan and Biklan (2007), phenomenology researchers seek to understand the people they are studying by searching for meaning in their shared experiences. They do not make any assumptions about what the truth is. With this type of approach, the researcher is supposed to state their own assumptions and bracket them to eliminate any personal belief, experience, or bias from the interpretation of the data (Creswell, 2009).

In Tracy's (2010) article regarding the characteristics of "qualitative quality," she delineates the eight traits that must be present for excellence in qualitative research. These eight characteristics for quality are: “(a) worthy topic, (b) rich rigor, (c) sincerity, (d) credibility, (e) resonance, (f) significant contribution, (g) ethical, and (h) meaningful coherence" (p. 839). While each quality criterion is important and understanding that research should not and cannot be conducted unless it is ethical, the researcher will focus on the four most relevant for the purpose of this research. First, a topic can be considered "worthy" if it adds relevant information to the literature instead of simply restating what already exists. Second, a study may be considered rigorous if there are abundant details provided about the participants and the contexts, as well as a thorough investigation into theoretical applications. All relevant details must be supplied such as time, date, place, and participant background. Third, research is "sincere" if the researcher is honest about 
the challenges that took place regarding the data collection, methods, and participants. The researcher also needs to be sincere and reflect on any personal biases and views (Tracy, 2010). Fourth, "credibility" is determined through rich description which attempts to "show" their observations from a neutral point of view, instead of "telling," where the researchers interpret their observations (Tracy, 2010, p. 843). Quality research also calls for the practice of triangulation. Triangulation is the research practice in which two or more researchers, data sources, types of data, or theories come to the same conclusion (Denzin, 1978). A similar practice that entails the use of multiple forms of data is called crystallization (Ellingson, 1978). In this study, the researcher used triangulation through the practice of member checking. The participants were sent summaries of interviews and the researcher's observations, and they verified the accuracy of the summaries sent to them. In addition, the researcher kept detailed field notes and a journal with personal opinions and perspectives to avoid bias and maintain transparency.

\section{Researcher Autobiography}

As the first-born daughter of Cuban immigrants who had settled in Paterson, New Jersey, I learned how it felt to be considered an outsider. When I first started kindergarten in a small Catholic school, I knew no English whatsoever. It was 1971, and back then, there was no such thing as English for Speakers of Other Languages (ESOL). There was a handful of other Hispanic children in the class, but I was the only one who did not speak English. I cried often those days, and my kindergarten teacher, Mrs. Dougherty, warned my mother that I would probably have to repeat kindergarten because of the language barrier. My mother decided that this was not acceptable, so she "hired" a 
bilingual 11-year-old Cuban girl to speak only English to my younger sister and me. She was paid with my grandmother's wonderful Cuban cooking. It might sound funny, but the strategy worked. By the end of kindergarten, I had learned enough English to be promoted to first grade, and my sister started kindergarten speaking fluent English.

At home, my sister and I lived with our parents and maternal grandparents in a very large apartment building. My father worked at a chemical plant, Fisher Scientific Company and cleaned two banks and Townecraft, a fine china company, along with my mother, sister, and I. We would wipe the desks, ashtrays, and windows, and then sit down to complete our homework. My parents sacrificed so that we could attend private school and they would be able to afford piano lessons, painting lessons, and math tutoring.

In school, I did well academically, but socially, not so much. Since I was considered "different" I would often get bullied by my classmates. I had a few close friends, and they helped to make school a more positive experience. Reading provided an escape for me, and of course, it improved my vocabulary tremendously. At school, I found that I excelled in spelling, and was the school's Spelling Bee champion for seventh and eighth grade. I would memorize the words with my mother who did her best to coach me. For seventh and eighth grade, my teachers had me sit next to a girl who had just arrived from El Salvador. I spent those two years translating everything from English to Spanish for every class. I became friends with the girl and improved my translating skills, so I benefitted from this too.

In high school, I attended an all-girl Catholic school. The nuns had a lot of activities for us, and I participated in the Glee Club. I also helped a Cuban girl who 
became a good friend of mine with her classes because she knew no English. At this point, there still were no ESOL classes available. At home, my parents were very strict and overprotective, so my sister decided to write to my aunt and uncle in Miami and ask them if they would be willing to have us live with them. We were surprised that my parents agreed to it. They decided that they would move to Miami in another year or so. When I began high school here in Miami for my senior year, it was quite a culture shock. I remember thinking that everyone was so "huggy-kissy," and I did not feel comfortable with the Spanglish either. I would often think that it did not make sense the way that Miami kids mixed both languages. By the end of the year, I had made many friends and adjusted to the way of life here. It was of great benefit to me that I had never forgotten my Spanish while I was living in New Jersey. I was happy to notice that it improved daily because I spoke it more frequently throughout the day.

When I took my SAT during my senior year, I was never informed that prep courses existed, so I took the exam without any preparation whatsoever. Of course, I did not score well, but fortunately my high school GPA was good enough to get me accepted to Florida International University, University of Miami, Rutgers, and a few others. My great-aunt informed me about the Coca-Cola Hispanic Scholarship, and I applied. I was accepted, and the requirement was that I maintain a 3.0 GPA. Thankfully, it paid for all four years of university, including books. I changed my major a few times because it was difficult for me to decide. I was interested in many areas, but I finally decided to major in English, and minor in Spanish. I was enthusiastic about becoming an English teacher, but I majored in English instead of English Education because I loved my literature classes and the professors so much. To get certified in Education, I took the courses on the side. 
At this point, I already had been working at a public junior high school as a teacher's assistant. A part-time Spanish teaching position opened there, so I taught Spanish for a year. Soon after, there was a full-time English teaching position at a nearby high school, so I transferred schools. After teaching there for three years, I was transferred to the ESOL Department at the same school. The University of Miami was offering study grants for individuals interested in obtaining a MSTESOL (Master of Science in Teaching English for Speakers of Other Languages) degree. I thought that it was a great opportunity, so I applied and was accepted. The university paid for everything including books and mileage. The only problem was that I was forced to take three classes at a time most semesters. After obtaining my degree, I kept on teaching at the high school for many years. During this time, I had a child, got married, and got divorced a few years later. It was very helpful to be able to supplement my teaching income by teaching ESOL to adults at the high school, and also at Miami-Dade College.

At the age of 35 , I started to feel sick and was diagnosed with lupus. I spent six weeks in the hospital, and everyone, including myself, was afraid that I was not going to make it. I tried to be strong and positive because I had a 9-year-old daughter who was depending on me. When I left the hospital, my perspective towards life changed in a positive manner. I knew that I wanted to spend the rest of my life helping people to improve their lives because I had been given the chance to continue living, and I wanted to be a positive role model for my daughter. After being on medical disability for a year, I recuperated enough to work full-time again. At this time, I suffered a devastating loss because I lost my father to complications from diabetes. Losing my dad plunged me into a deep depression, but I sought help and began teaching ESOL at a charter school. After 
two years of being at the charter school, I decided that it would be in my best interest to return to the public schools because they offer a pension and have a teachers' union. I switched to a public middle school and taught Spanish and English for six years.

I felt that after this time, I needed to make the switch to a high school setting because I missed it. Thus, I applied for a position teaching SPED English and Journalism (Yearbook). I acquired new skills at this workplace that I never thought I would learn. For example, I did not know how to break classroom instruction down to adapt my lessons for students with learning disabilities, and I did not know how to put a yearbook together either. Consequently, these were years of growth for me as a professional. At the same time, I was working on my doctorate by taking one or two classes at a time. My daughter was in her senior year of high school, so that was a challenge as well. Despite all the challenges, I felt proud of myself at the end of the year because my students and I were able to publish a yearbook and my daughter obtained her high school diploma.

Two years after my daughter graduated, my mother passed away from a cerebral hemorrhage. It was difficult to experience the emptiness following the death of my biggest cheerleader. She had always motivated me to follow my dreams and to be the best that I could be, and I felt lost without her support. I found the strength to continue through my faith in God and because I knew that she would have wanted me to never give up.

After four years at this high school in Hialeah, I obtained an ESOL and Journalism position at an inner-city high school and taught Haitians and Hispanics from the Caribbean, Central American, and South America. I am still working at this high 
school, and I have also learned many teaching strategies and how to adapt new technology for use in the classroom. I have discovered that I enjoy applying what I learn for the benefit of my students, my family, and friends. My family has expanded to include three new granddaughters and a grandson, and I enjoy seeing the world through their eyes. It is this enthusiasm and joie de vivre that I hope to apply from my research, so that students who are new to this country and aspire to succeed do not feel daunted by the challenges they face. It would truly bring me great satisfaction to witness the success of immigrant students because they realized that if they put their mind to it, nothing is impossible.

The researcher is aware that the findings could be influenced by my gender, culture, history, and socioeconomic background. For instance, due to traditional gender roles, especially in Hispanic cultures, it is not as easy for women to obtain opportunities to further their education. It has been my experience that women are thought to think of careers that are "family friendly" such as teaching, due to their hours and vacation days, when choosing a career. Women are also told to put "family first" if they choose to pursue a degree after they have started a family. As a Cuban-American, I was taught from an early age that college was important, but it also conflicted with my gender role as a woman. Throughout my life, I knew that I wanted to further my education, and the thought of not doing so never crossed my mind. I knew that the best way to ensure my future possibilities would be to study as hard as I could so that I would never have to work long hours at a minimum wage job. My parents instilled that in me, and I also believed in the American Dream too. My mother would always say that there was never an excuse to not study in this country because of all of the opportunities and the financial 
help available. Due to my experiences as a first-generation Hispanic English language learner myself, I must set aside my biases and consider the experiences of the participants as unique and apart from what I experienced.

\begin{abstract}
Assumptions
The assumptions that the researcher has for this study regarding how academic self-efficacy and the use of self-regulation learning strategies may be linked to persistence on ELLs have been the following:
\end{abstract}

1. The researcher is likely to learn something new that was not covered in the review of the literature.

2. Students who start college intend on completing a degree.

3. First generation students are more motivated to succeed than second generation students.

4. Students who are low in academic self-efficacy will struggle to persist, but the opposite is true of those students who possess academic self-efficacy.

5. Students who lack self-regulated learning strategies are less likely to persist, but the opposite is true of students who possess self-regulated learning strategies.

\title{
Sampling Methods
}

After appropriate guidance by both Florida International University's and Miami-Dade College's respective Institution Review Boards, the researcher utilized criterion sampling to search for prospective participants, which is obtained by using participants who meet certain criteria (Creswell, 2009). If additional participants were needed, snowball sampling was utilized. In snowball sampling, current participants help the researcher by recommending other participants with the desired characteristics 
(Bogdan \& Biklen, 2006). For this study, the inclusion criteria included: 1) Hispanic male or female student (preferably first-year), 2) adults 18 or over, and 3) designated as an ESOL Level 3 or higher, (which is considered intermediate to advanced proficiency in ESOL) according to their college class to afford being interviewed in English.

In this study, I sought for participants through word-of-mouth and through the snowball method. Every time I found a new participant, I would ask him or her to recommend a friend or acquaintance whom they thought fulfilled the necessary criteria.

\section{Participant Selection}

In a phenomenological study, the researcher's main concern regarding participant selection should be if the participant has the requisite experience (Englander, 2012). The participants in this study were Hispanic ELLs who attended college in South Florida and were 18 years of age and over.

Although Creswell (2014) recommends that the population size for this type of study be from 3 to 10 participants because data saturation is typically attained with this number of participants, the researcher sought and found 14 participants to afford better coverage of their experiences.

Almost all the 14 participants in this research were foreign-born, except for Estefanía and Gisela. Rosa arrived in the U.S. before the age of 2. Rosa, Estefanía, and Gisela were included in this study because they only spoke Spanish at home, so they also had to adapt to a new language at school. In addition, their parents were recent arrivals to the United States. The participants' arrival ages ranged from under 2 through 18 years of 
age. Table 1 below presents the participants' age, nationality, age when arrived in the U.S., and if they entered a college or university when they began their studies.

Table 1

Participant Information

\begin{tabular}{lclcl}
\hline Pseudonym & Age & Nationality & Age When Arrived in the U.S. & Coll/Univ. \\
\hline Rosa & 19 & Cuban & Under 2 & University \\
Danilo & 21 & Cuban & 11 & University \\
Mayra & 19 & Ecuadoran & 14 & College \\
Karina & 19 & Honduran & 14 & College \\
Oscar & 19 & Nicaraguan & 13 & College \\
David & 24 & Cuban & 11 & College \\
Charles & 20 & Dominican & 18 & College \\
Estefanía & 27 & U.S. (Mexico/D.R.) & Born U.S. & University \\
Cristóbal & 19 & Dominican & 16 & College \\
Lorenzo & 19 & Mexican & 7 & University \\
Gisela & 19 & U.S. (Cuban) & Born U.S. & University \\
Gregorio & 20 & Mexican & 16 & College \\
Sofia & 32 & Peruvian & 15 & College \\
Rafael & 29 & Peruvian & 12 & University
\end{tabular}




\section{Data Collection}

The researcher conducted 14 in-depth, semi-structured interviews in English.

Semi-structured, interviews are characterized by rich detail, open-ended questions, and these questions do not have to follow a specific structure (Rubin \& Rubin, 2012). The semi-structured interview was used as opposed to a structured interview because it allowed for much richer exploration of the participants' lived experiences. In a semistructured interview, "the researcher has a specific topic to learn about, prepares a limited number of questions in advance, and plans to ask follow-up questions" (Rubin \& Rubin, 2012, p. 31). After getting to know the participant for a few minutes, the researcher conducted the interview using a written guide of planned research questions along with appropriate probes and follow-up questions to facilitate discussion. The researcher used an iPhone to record the interview, and a digital voice recorder for backup. In addition, the researcher took field notes immediately after each interview to record the context of the setting and other pertinent observations. This took place immediately after the interview, to prevent the researcher from forgetting any observations made during the interview process. After collecting all the interview data, it was transcribed and was checked for accuracy (Rubin \& Rubin, 2012). Once the themes were derived from the data, each participant was contacted for their feedback. The participants agreed that in general the six themes captured the essence of their experience as Hispanic first-year learners persisting in college. Some of these participants also wished to add extra comments about their experiences. 


\section{Data Analysis}

For this phenomenological study, the researcher used Excel to code and identify themes in the data. "An Excel spreadsheet is essentially a database with each row being a record" (Meyer \& Avery, 2008, p. 18). This coding method was chosen because it is easy to use, and the researcher can save time by not having to learn how to use a software program such as NVivo.

The researcher transcribed the interview data through rev.com, a professional transcription service. Additionally, the researcher maintained the integrity of the research by safeguarding the anonymity and privacy of the participants. Each participant selected a pseudonym to keep them anonymous. The researcher saved each transcribed interview in an online file with each participant's pseudonym.

The coding system utilized for this research study was developed through creating codes based on themes that recur in the data simultaneously with "coding families," a method that was created by Bogdan and Biklen (2007) to develop coding categories and sort data (p. 174). and Bogdan and Biklen's (2006) suggestions to develop a list of initial codes to assist making the data analysis more manageable. The researcher designated categories for participants' backgrounds, parental backgrounds and education, transition to this country, who helped with transition, age at time of transition, country of origin, etc. Bogdan and Biklen had suggested codes for setting, participants' views, activities, process, etc. because these generic codes could be applied to most phenomenological research. After this initial coding system was established, it would be easier to become more detailed and specific with coding, depending on what themes emerged. 
The researcher prepared the transcription for transporting to Excel by doublespacing between sentences, the interviewer, and the interviewee (Meyer \& Avery, 2008). Once the interview was transported to Excel, the researcher coded the transcription assigning letters to each code and by creating a separate tab with a code name. Then the researcher cross-checked the coded analysis with her field notes to determine whether any other observations could be added to the analysis.

\section{Validity and Reliability}

In qualitative research, validity refers to the researcher checking the accuracy of one's findings, while reliability indicates the researcher's consistency across different researchers (Creswell, 2014). Creswell (2014) recommends a number of strategies to check for the accuracy and therefore validity of the findings. The researcher used the following a number of strategies to check for accuracy. First, participants were sent the transcripts and asked to review the themes to determine the degree to which the participants felt they are accurate (i.e., member checking). Next, the researcher also used two additional different sources of data were used to build justification for the themes that emerged from the data. The three sources were data from the member checking, semi-structured interviews and field notes. Utilizing three different sources of data (data triangulation), if they converged, provided strong accuracy or validity evidence. Third, the researcher used rich, thick description to communicate the findings, including focusing on the setting, which made the results become more true-to-life and therefore richer. Fourth, the possible bias being brought into the study was clarified by the researcher (see bracketed autobiography) through discussing how interpretation of the 
findings may be influenced by her gender, culture, history, and socioeconomic background. On the other hand, reliability was handled through providing an account that describes the study's purpose, the researcher's and participants' roles, selection criteria, and constant comparison of codes with the data to make sure the meaning of the codes did not drift, and cross-checking the codes with a trained researcher (Goetz \& LeCompte, 1984). In addition, a peer reviewer was used to cross-check the codes. As recommended by Creswell (2014), a minimum of an $80 \%$ level of agreement between the researcher, the trained researcher and peer reviewer was sought, but discussion of the theme continued until $100 \%$ agreement was attained.

\section{Summary}

In this chapter, the phenomenological method was presented as the type of qualitative research lending itself best to answering the research questions. Rich detail and description were utilized to highlight the similarities that the participants shared as ELLs, and also their diversity as individuals. Member checking, field notes and the semistructured interviews served as means to triangulate the data. The researcher's autobiography discussed how being a first-generation student influenced her to help others who are being challenged educationally as well, but also helped her bracket these personal experiences when attempting to interpret the findings. Finally, the researcher discussed how Excel was used to track and code the data and the efforts undertaken to obtain validity and reliability evidence. 


\section{CHAPTER IV}

\section{FINDINGS}

This chapter describes the experiences of 14 Hispanic college students who learned English as a second language when they were young children or adolescents. The purpose of this research was to understand the experiences of $1^{\text {st }}$ generation Hispanic English language learners during their first year at a Hispanic-Serving Institution. The researcher also sought to understand how their childhood and adolescent experiences helped them make it to college, which experiences from their childhood and adolescence posed a challenge to their academic success, what special people helped them along the way, if they had any role models, how anxiety affected them academically, and how their academic strengths and weaknesses helped or hindered them with their studies. An inductive approach was utilized to analyze the data for recurring themes. The five themes that emerged from the data were: (a) families and teachers encourage goal-setting and motivation, (b) the power of motivation in the pursuit of the seemingly elusive American Dream, (c) difficulties in navigating the higher education system as first-generation college students, (d) friendships and the role they play in the participants' lives, and finally, (e) uncertainty of the future and participants' expectations after graduation.

\section{Families and Teachers Encourage Goal-Setting and Motivation}

One of the first themes that emerged from the data was the encouragement to set goals and the motivation that the participants received from their families and teachers, which mirrors Tinto's (1988) notion that level of support is a primary characteristic of students who persist in college. Many of them had stories to tell of parents who sacrificed 
their dreams and everything they had ever known for the promise of a better future for their children. Some teachers who went above and beyond also stood out as having made a significant impact in the lives of their students.

The participants provided many examples of parental support. Oscar noted how he was helped with his transition to Miami (Nicaragua), he explained:

"Well, I think my parents were always ... to help me, always motivate me, always give me ... support me and everything. And, I think that they were the only ones with me, helping me get through the process of learning and going to school and all that."

When the researcher asked Cristobal about his educational goals in his home country (Dominican Republic), he stressed how much his mother had discussed the importance of working for your goals:

I was planning to finish my high school 'cause my mom teach me from the beginning: "Oh, you will be responsible for your stuff. If you wanna be nobody in the future, that's your problem. If you wanna be somebody that can do a change, it's your responsibility." So, I don't know, like from 2nd grade of middle school I'll be responsible for my own stuff, so she didn't tell me: "Oh, go to school." I go 'cause I want to, I wanna like learn and I wanna like study my own thing and learn. And that's the thing where you say: "Oh, you learn everything...something new every day." So, yeah, from the beginning I be responsible for my own stuff.

In another example, this was Lorenzo's response to what contributed to his success:

I think, other than the hard work that I've applied, definitely my family has been hugely instrumental in my education, just simply as like ... earlier you mentioned was there ever a big change and the fact that I can say no, that through college and through my education, my family has been steady. Like I didn't have to go through a divorce or a separation of my parents or major health issue. I always had a house to live in and food at the table, so I don't have that sort of preoccupation or worry about it, so that's the major that. And also that part of working with my family, I was earning enough to be able to pay for school and I had to pay out-of-pocket, 
because I'm not a U.S. resident or citizen, I don't qualify for financial aid or anything like that, so being able to work with my family and being able to earn enough to pay out-of-pocket was definitely the biggest thing that helped me.

When asked what her educational goals were when she was a child, Gisela answered:

Well, my mom always had me getting good grades. Bad grades were just not acceptable in my house so my entire life pretty much has revolved around school. I think because of that I'm who I am today, like a hardworking person and student. My mom always wanted the best for me so because she was unable to get much out of her education in the Dominican Republic and she moved here kind of late in her life, she found it important for me to take advantage of the American education system and do as best as possible, and go to college and university. So that kind of led me to where I am now...

The participants had positive feelings towards their elementary, middle, high school teachers and professors. A group of participants felt that they would not have made it as far as they did without the help of these educators. Rosa had this to say when asked about her first school experience:

In elementary school, I went to South Hialeah from 1st to 5 th grade and I think that was a really good school. I had really, really good teachers. My teachers were very nice. I mean, they were nice when they needed to be, but strict and stern when they also needed to be. I had really good teachers, that some teachers were very encouraging. I remember my 2 nd grade and my 5 th grade teacher, they would just praise me a lot and just tell me, "You're a really good student." I think that kind of gave me confidence at such a little, young age to do better than my classmates.

Rosa felt that her elementary school experience had served her well because she was given support and structure at the same time, which helped her succeed in her future studies. Karina credits both her mom and teachers for encouraging her to continue: 
First of all, was my mom. There were days when I didn't really want to go to school, and she would always be like "you need to go, you don't know what's gonna come ahead of you, you should go."

Second of all my teachers. Also, my cousins, they were always encouraging me to do better, to learn more, to adapt. It was okay if I failed. They would always encourage me to keep learning.

David talked about one of his science teachers, and how this teacher helped them

to look beyond the labels:

He used to work a lot with Mr. V. to try to get us to look outside the box, and I think because we labeled ourselves as ESOL kids and that's how we saw each other, but their whole point of view was you can't look at yourself that way, you have to look beyond. You're not an ESOL kid, you're a kid, you are developing in your studies you need to look forward to college you can't be labeling yourself now and put trust in yourself.

Some teachers helped the participants develop their writing skills and a love for

the subject matter. Gisela expressed it this way:

A teacher ... Oh, in fourth grade we have to take the Writing FCAT, and I remember my writing teacher Miss A., she was always very helpful with writing and stuff. She was probably one of the best writing teachers I've had because well, first of all she built the foundation that I have to write, which I love writing. So I think that it must have stemmed through her because she was the first person to teach me how to write a proper essay and get creative with my writing and such.

A few of the participants were inspired by their college professors. When asked

what teachers made her feel more comfortable, Estefania responded

A teacher that helped? I've had a lot of teachers. Well, as an adult. Professor M. has made me feel better about college. She's very helpful. I've taken English before at another college and I didn't do as well as I'm doing now. She is teaching me and she's a very patient person. I've learned a lot from her. And I kind of don't remember my teachers as much, so that's why I'm using Professor M. as an example. 
As evidenced by the comments above, the support received from parents, teachers, and other family members, laid the groundwork for future success the participants spoke about how their family members and teachers motivated them to succeed and never give up, even if there were obstacles along the way.

All 14 of the participants had been inspired to succeed by adults in their lives whom they admired, such as a parent, teacher, older family member, significant other, and friend, which parallels Bandura's (1997) idea that role models could be powerful sources of efficaciousness beliefs about performing well academically and persisting in college. The participants described the positive impact these role models had on their lives.

Cristobal replied that his girlfriend was his motivation to continue his education:

Yes, my girlfriend. Well, by that time she was not my girlfriend but she was a nerd. And I will say: "Hey, she was a nerd." And she is. But she was always telling me: "Do your work, do your work," when I was lazy. And now she's going to UF and I try to break my neck in college so after two years I can go to UF and probably take classes with her.

Estefania looked up to her older cousin as a young girl because she was attending university:

I did have an older cousin. I think they were in college at the time. I think it was my cousin. She was going to UM. I used to look up to her. I think she went to UM. I don't know, it was a long time ago. But she was my first cousin to graduate out of the family.

When I asked Gisela if she had someone had inspired her to continue her education, she replied:

To be honest, my mom is my role model. Although she didn't really get much of an education in college, she was always my inspiration because she made a lot out of what she had. She's always been a really hard worker despite not getting an education, like such a strong foundation in education. And when she went to school in the Dominican Republic, she went to school to be a secretary because 
that was really because of what her dad made her do, because that was kind of like a woman's job over there. She always inspired me to go beyond that and go beyond gender roles and stuff. So she was definitely my role model when it comes to school. And she always told me to get good grades. She was always very hard on me.

Sofia had a similar answer:

Yes. My Mom. My Mom. Definitely, my Mom. She's a role model. She went to University when I was a like around one. I remember her taking me to University with her. You know the teachers would take care of me while she was taking a test. For me, she was a super Mom and she's my role model. That's why I want to do this for her. I want a finish my college because of her. She is the only reason why I want to do this.

Rafael's father's advice made a lasting impression on his future career choice:

But he got so ... that is, his engineering degree, he worked his mind off, he was able to found himself four or five different companies some of which are still running over there. And even though he suffered financial setbacks and got divorced and what not, he was always the one that I'm like, 'listen you gotta go, it doesn't matter what it takes, it doesn't matter how long it takes you just gotta go get your degree even if you don't end up using it, you have something to fall back on, like that's something that you need to take care of that.'

These role models led them through their strong work ethic and desire for these young people to succeed. This strengthened the participants' resolve to continue the struggle because they would always be there to guide them.

The Power of Motivation in the Pursuit of the American Dream

The American Dream is defined as "the ideal by which equality of opportunity is available to any American, allowing the highest aspirations and goals to be achieved" (en.oxforddictionaries.com, 2018). All the participants or their parents arrived in the United States searching for a better life for themselves and their families. Reasons for leaving their countries of origin included improving their financial situation, obtaining a 
better lifestyle, seeking educational and employment opportunities, escaping corruption, and following family to the U.S.

The pursuit of the American Dream was present in all of the participants' interview responses in some way or form. The researcher did not directly ask the participants about the pursuit of the American Dream, but the subject often came up as a response to "What were the reasons that brought you here?" In each case, the participants spoke of how either they or their parents left everything and everyone they knew in search of a better future. They also described the challenges they experienced when adjusting to their new lifestyles-learning a new language, finding a place to stay, searching for employment, going to a new school, and the process of documentation.

Rosa, whose family emigrated to Miami from Cuba during an extreme financial crisis in Cuba precipitated by the dissolution of the Soviet Union, remembered as the "Special Period" when she was only a toddler, describes it this way:

Yeah, I think financial reasons might've been the biggest motive. I was born during the Special Period in the '90s and my parents had applied for the visa in 1993. They applied before I was born. You can only imagine having twins, because I have a twin sister that would've added to their financial burden. I think it came at a good time in their lives. I think there weren't any issues with the government or anything like that, that I know of.

Danilo remembers leaving Cuba at the age of 11, and responded, "I just kind of migrated with my parents just in the search I guess of a better life." In contrast, Mayra's family simply followed her father to Miami. She explains: "You know he did the process to get the visa and everything? That was the reason, the major reason what I came to this country, to be honest." She admitted that even though she had moved here due to her 
parents' decision, she would not have had the opportunity to study medicine. She describes it this way:

Yeah ... Not really because my mother didn't have the money to pay me for Med school because in Ecuador after you do high school you go directly to Med school. So we basically were talking about if I'm going or not but I wasn't sure if I was going to Med school.

For Karina, there were several reasons for leaving Honduras: “...especially in the financial area, it was very tough being over there. Also, wanted to see my mom too. Different way to succeed. I got to study here.” Due to financial difficulties and not having her mother's support in Honduras, Karina knew that it would be difficult to go to college if she stayed in her home country. For Karina, success is equal to a college education. She stated:

As many people say, success is a path not a destination. Every day that I wake up and am reminded that that day I will go to college, I feel successful. All that I went through to high school, even though there were good and bad days, I just feel motivated to go.

Getting a good education motivated Oscar to come to the U.S. when he was 14:

"Well, first of all it was for my education. And yeah, that is basically why I came here to get better and study and be someone in life, a professional.”

David's parents also left Cuba for the same reason as Oscar: "My parents wanted me to have a better education. I did not have an option obviously because I was 10 years old so that's the main reason because I wanted to like have more options for me and my sister."

Charles left the Dominican Republic for financial reasons: "Dominican Republic, they are a good economy, so we come to here, a better economy." 
Estefanía's parents are Salvadoran and Mexican; she was born here. Her parents did not have it easy in their native countries, particularly her mother who has been working from the age of six. She explained:

They left ... Well, my mom started working when she was like six years old. She didn't really go to school so she wanted to make more money, so I guess that's why both of them came over here. For a better future for themselves.

For Cristobal, there were various reasons why his family decided to come to Miami:

Well, my mom got marriage with somebody that was living here, so he say: "Oh, why you guys don't came here to the US?" And we see it like a good opportunity for us 'cause there are more jobs and they take more serious the education here. So we say: "Oh, let's go there." So, now we're here.

Gisela was born in the U.S., but her parents sought a better life away from the corruption in the Dominican Republic, as well as to remain together as a family:

I think it just was because ... well, obviously they wanted a better life here. 'Cause they're from Dominican Republic and although it's not as bad some other Latin American countries, there's definitely is a lot of corruption. Also, my mom's sister moved to Miami and her mom moved to Miami too so she just followed around.

In Gregorio's situation, his mom made the decision to leave Mexico for a better

future for herself and his family:

It's not my reason, right, the reason was that my mom, she want the better future for my brothers and for me and she moved to Miami because she say we really need money, the economy in Mexico is really bad so we moved to Miami for the economy reason.

Sofia's mother also sought educational opportunities and a new life:

Okay. So my Mom wanted a better teacher for me. She wanted me to go to college, go to university. She's wasn't gonna be able to live by herself over there in Peru, so that's the main reason why she brought me here. Why we moved here. Rafael's family wanted to look for new financial opportunities in the U.S.: "I 
know that for some Peruvian families, there was issues with terrorism back in the early

'90s, but for my family itself, was economic, the reason why we came here."

Because adjusting to the U.S. was such a significant undertaking, almost everyone in the study had family members or good friends who helped them make the transition.

Karina was fortunate to have several family members help her financially and

emotionally to make the transition: "Yeah, my mom and also my dad, my stepmom and

my grandma. They support me financially and emotionally too."

Oscar believes that his parents also supported him not only financially, but through their words of encouragement as well:

Well, I think my parents were always ... to help me, always motivate me, always give me... support me and everything. And, I think that they were the only ones with me, helping me get through the process of learning and going to school and all that.

In David's case, family helped, in addition to the government assistance they received under the Cuban Adjustment Act. The Cuban Adjustment Act began to be called the "Wet Foot Dry Foot" policy because it allowed Cuban refugees to stay and become U.S. residents if they made it to land before they could be turned away at sea by the U.S. Coast Guard (the policy was still in place at the time his family arrived). The policy, which began in 1995 under President Bill Clinton, was ended in 2017 by President Barack Obama (Gonzales, 2017).

We got ... I think we there was a wet foot dry foot something like that so I noticed there were some government incentives for us so we receive help from a church but that was associated with government package, A package or some reason and 
then my grandparents live here and we have a big family here so they helped us move along and do all the paperwork and everything we needed here.

Rafael thinks that both his family and the Deferred Action for Childhood Arrivals

(DACA) were instrumental to his success:

Well, prior to having DACA, when I graduated high school, and for the most part of growing up, there was no DACA. There was also no in-state tuition. When I started college back in 2008 , I had to pay ... No, I've always had to pay out of pocket, but I had to pay tuition at my immediate college. I was working and getting paid under the table. I didn't have a driver's license. As soon as DACA came in, as soon as we won DACA back in 2012, mine got approved in the summer of 2013. So, I was able to get a job that paid a decent wage. I was able to get a driver's license.

Learning a new language can be a difficult challenge, but the participants felt that

they were supported by their teachers and peers in this endeavor, for the most part. The participants felt that the existence of a large immigrant population in Miami made the learning environment welcoming.

Danilo’s experience was somewhat different than most of the participants. He moved with his family to Orlando, whose Hispanic population is not quite as large as Miami's. He felt that he really began to acquire the language when he spent more time with friends who only spoke English. The following is what he had to say about his first educational experience in the U.S.:

Okay, well middle school. That was a little rough at first. Not too bad. I'm kind of a quiet person so it wasn't too hard for me to stay quiet until I got a better hold of the language. I made some friends with obviously at the beginning a little bit more Hispanics, but after that I kind of branched out a little bit and just because of sports and basketball and stuff like that I started hanging out with people who always spoke English and I think that was big in learning to socialize, learning to speak their language. And then transitioned in high school, it felt natural by the time I got to high school it was just ... Middle school was just the transition period and high school was just a normal time for me with normal friends and normal classes. 
Karina thought that her high school experience learning English led to her being capable of doing well in her classes in college, "Alright. Going to high school was challenging. Especially cause I overcame a language barrier. I got to take ESOL classes, which of course, helped me a lot. The language that I know is because of it."

Charles also felt the same way about learning English, especially because he was older when he arrived in Miami:

Yeah. You know, I had some friends. I asked them ... those guys who talked Spanish 'cause it was really hard for me speaking English and understand the professor when they tell me something. They help me. They help me a lot. Those classes, learning English, I had a professor who ... Mr. A. He helped a lot. He was a good professor for me, and he helped me a lot.

Sofia was challenged not only by the language barrier, but also by having to begin college after a seven-year gap. Although she had exited from the ESOL program in high school, she felt uncomfortable with her English skills when she started at Miami-Dade College:

Okay. I was very nervous and I was feeling insecure because my English. I understand and I can speak it, but it's not perfect probably like somebody who was born here. So I was feeling very insecure. I was thinking like people where gonna make fun of me in the way I talk, the way I say things, the way I pronounce, my accent, but it was actually a good experience. Nobody makes fun of you. They help you.

When the participants arrived in the United States, they had dreams of being successful in the future. They felt inspired by their parents' work ethic and how they struggled to offer them a better lifestyle. Regardless of whether their parents were college-educated or not, they either wanted to follow in their parents' footsteps or do their best to achieve so they would not have to struggle like their parents had. 
Although Karina is still a young adult, she expressed that this has been her experience with all the parents regarding their intentions for their children's futures:

Ask any parents that will put their kids to study, they will always say that they want a better future for their kids. That was my intention, getting something different from what my parents did and it has been like this ever since.

Gisela spoke similarly regarding parental expectations about education:

Well, my mom always had me getting good grades. Bad grades were just not acceptable in my house, so my entire life pretty much has revolved around school. I think because of that I'm who I am today, like a hardworking person and student. My mom always wanted the best for me so because she was unable to get much out of her education in the Dominican Republic and she moved here kind of late in her life, she found it important for me to take advantage of the American education system and do as best as possible, and go to college and university. So that kind of led me to where I am now.

\section{Difficulties in Navigating the College System as First-Generation College Students,}

Despite the hardships and struggles to move to the U.S., the participants still had another large challenge to overcome. Each of the participants had to learn to navigate the higher education system and overcome barriers (Cross, 1992) to be able to attend classes, juggle work and family responsibilities, and pay their tuition or obtain financial aid.

The participants in this study all expressed the intent to persist until graduation, with some of them intending on pursuing graduate studies. Cristobal expressed his struggles with work and studying this way:

Yeah. In my family, 'cause I wasn't there whole day until 21:00. But in my employment status, I had to quit from my job 'cause I knew that my studies were more important. So I need time to do my work, so I say: "Oh, I'm gonna quit." Even though I can find another one but I need time to do my work, so I decide to quit from my work. And probably I will find another one in this semester or something, next week, probably. But right whenever I need time to finish my work, I prefer to quit from my job so I can finish my work and have good grades. 
Lorenzo believes that most of his struggles were due to his undocumented status:

I'd say no. I think the biggest obstacles was first not [inaudible 00:45:31] because I was documented and then I've managed to ... it has been difficult at times to pay for my tuition because I pay out of pocket. It has been difficult at times, but I've managed somehow to scrape something or pay with a credit card and make up, so I think definitely finance has been a difficulty, but I've managed to do it or managed a way around it, so, but I think that's really the only thing that's been a barrier to me and my studies.

Despite having been born here, Gisela and her family still struggle. She receives

financial aid, but it is not enough. To her, the main obstacle was:

My family doesn't have a lot of money, so I definitely have to work in college in order to get by, I think, and not be so deep into student debt. I'm currently working three days a week. All afternoon, which kind of takes the fun out of school. And compared to most of my friends who don't have to work during college to get by. They definitely have more time than I do so it kind of sucks that I have to work, but I've got to.

Sofia seems to struggle the most between juggling family responsibilities, full-

time employment, and college due to how her life has changed the third time she attempted to go to college:

Yes. Actually, yes. I have to ask my Mom to help me with the kids because after get out of work, one I usually pick them up and take them home and do homework and do whatever I need to do with them. But since I'm going to school after work, I have to pick them up, drop them off at my Mom's house and she's the one who actually takes care of them after 6 . And then the next day, I have to get up early so I can pick them up from my Mom's house and take them to school and then I can go to work. It's a lot. It's a lot. I'm tired. By Monday night, I'm already dead, but I have to do this. So yes, there were a lot of changes.

In Rafael's case, his undocumented status interfered with completing his degree in four years. His hopes of attending the universities of his choice were also dashed. Due to having to work full-time to pay for his classes, he has spent ten years trying to complete his Bachelor's degree. 
My intentions when I started college was to finish in four years. I guess I hadn't come to full realization that me being a college student was not the same as my classmates, my high school classmates being college students, because I could not afford to pay full time. I have to work. I did not get any federal aid. I wanted originally to do two years and transfer to UCF and UF as soon as I was done, but given the reality of the situation where I had to work to pay. I was always working to pay the next semester. That unfortunately did not become a reality. Unfortunately, 10 years later, I'm still here, but I have decided as always to keep moving forward and finish my degree either way.

In addition to these challenges, the participants experienced difficulties with subjects like mathematics and writing. Other challenges included time management and procrastination. Zimmerman (2000) talked about how procrastination and time management were major self-regulation issues for college students, especially for those who are nontraditional and have to work to support their studies.

Rosa describes her difficulties with procrastination and math:

My academic weaknesses, I can tell you one right now is procrastinate. I don't know if that's a weakness, but I procrastinate a lot and that really hinders ... I could do so much better with my assignments and my work. I could be giving $100 \%$ but right now, I think I'm just giving like 75 . That's been enough for me to get good grades, but I like to do better at my classes, but I could be giving more. I think that's just because I burnout very easily. If I have a lot of stuff to do in a week, then I'll just sort of ... Just I'd rather take a nap instead. I don't know if that's an academic weakness but it's definitely a weakness of mine. In terms of academics, like subjects, math. I'm not very good in math. Thankfully, the majors I picked don't really require much math, thank God, because I just ... the two last courses that I had to take required, I got Cs on both of them and that was enough to pass, I was very happy. Thankfully, I don't take that anymore. Yeah.

When asked if she had sought help for her procrastination, she responded:

No. I've so many things going on, to sit down and reflect on why I'm not as successful with something than with other, I just don't think I have time. I don't think I want to mentally sit down and think about that, because sitting down and admitting you have a weakness is something I don't many people want to admit that, you know? So. 
Some of the participants like Sofia, Oscar, and Danilo felt they lacked time to obtain help with their weaknesses, acknowledging that it would be helpful, but perhaps some of them felt more like Rosa did. It could be they were unwilling to admit their weakness for fear it would cause others to change their impressions of them. This suggests that their efficaciousness levels may have been low. Those who are highly efficacious are more likely to take risks, making themselves vulnerable to someone else in a learning setting by admitting weakness, for the sake of learning (Bandura, 1997). This may also be linked to the participants' self-concept as a learner (Knowles, 1990) as well. It is not unusual for adult learners to have poor learner self-concepts and the thought of making oneself appear weak in front of their peers or instructors can be perceived as being problematic at best.

Mayra also felt that she had a problem with procrastination when asked about her weaknesses. When asked how it had hindered her, she answered:

Because last week, I needed it to do this math work and I was saying, "Oh, I'm going to later and later." Until the day after I realized I had to do a tons of work in just one night.

When asked how it had affected her test, she said,

"It didn't affect but I was then all night up and the next morning I was so much stress and everything because I didn't sleep well."

Danilo's response that his weakness was the subject that many of the participants also struggled with: math. He explained:

I'd say mathematics. I guess that changed at some point during high school. It just became a little tougher for some reason and it's still the hardest subject for me ever since sophomore year high school.

When asked how this weakness in math had hindered him in school, he 
responded "By lowering my GPA when it comes to math classes. And I guess

also when it comes to certain areas of science and physics and chemistry."

The students had different reactions when they experienced college life for the first time. Most of the participants would be considered nontraditional students because they are commuter students who work and go to school part-time. Some of them are older than traditional students. For the most part, they felt both excited and anxious about beginning their studies in college because they did not know what to expect. Some of them felt that they would feel out of place due to their language barrier or because they would not fit in. Others were surprised to find themselves out of their comfort zone because they had been active and popular in high school.

Rosa described her experience adjusting to university life as a traditional student like this:

It was a really overwhelming experience. Because I lived in Hialeah my whole life, I've never been in an environment where there's so many white people. It was really crazy to me. But, I was kind of thankful for the UF Housing Department because when I lived in my dorm, I was paired up with two other Hispanic girls. That sort of made the transition a bit easier, but I just remember noticing just how many white people there were in my class. Also, that transition from studying from high school to college was very difficult for me. I remember in my first semester, I had to drop a class because I hadn't developed good study techniques and that kind of didn't develop until my sophomore, junior year. I really did struggle a lot in my freshman year with that.

I just remember having no money, being poor. There's a really big contrast here at UF, especially coming from Hialeah. I remember having no money, but I think that can also be because of the way UF does its financial aid. I made a different process the next year and was able to get the direct deposit to my account. I have money now, so that's good. Out of the four years that I've been here, that was honestly the worst year for me. I think also, I didn't really have that many friends. The people I knew were just my classmates and the people that lived in my hall, 
but I think now that's different. I actually have a really good group of friends and stuff that I can go to. So, yeah.

In the interview Rosa spoke of not just having to adjust to a new culture, due to having lived in a predominately Hispanic culture all her life, but having to acquire time management and study skills, learning how to apply for financial aid, and making new friends.

Rosa's experience contrasts with David's experience at Miami Dade College because he felt that it was an extension of high school:

It felt very much like high school. It's just you had a little bit more freedom. I think there's less engagement by the students in college because High School ... I would consider college more like a senior year. Actually, no, I would consider the freshman time in high school and freshmen courses in college feel the same way it's like nobody really wants to talk to anybody. It's like the students are engaged with the professor and the professor tries but then every semester feels like freshman year high school.

Estefania explained why she did not feel comfortable in the college environment:

I felt nervous. Stressed out a little bit because after being at work all day and then going to school, sometimes my brain was fried because I'd been using it all day at work and then I'd come to school. So that's a little difficult. And sometimes I'm a little intimidated by the teachers because I don't know if I'm going to be able to have a ... I don't know how my relationship is going to be with them.

When discussing the participants' academic strengths and what led to their

success so far, the researcher received a variety of answers. It was important to discover whether they were aware of their academic strengths and if they believed that they were responsible for their academic success (Bandura, 1997; Knowles, 1990). In this study, the participants attributed their success primarily to their writing and communication skills in English, math skills, and tenacity, while some gave credit to their families and fellow students for helping them achieve. 
When Rosa was asked by the researcher what she considered responsible for her success, she attributed it to her ability to plan. She replied:

I think my planning, I'm really good at planning and that's kind of difficult to do when you have so many things to get done and so many classes that require readings, and assignments, and project, and stuff like that. But, I think planning is the number one thing that everyone should learn how to do more, just have with them because we have three assignments due that day and you kind had to prioritize what's the most important.

Danilo, on the other hand, noted that he received help from his peers with handling class assignments and studying for tests. Danilo was not sure, but he noted that, "I guess I receive more from my peers than anything else?" Further, some of the participants, like Estefanía, Rosa, Cristobal, and Danilo mentioned the value of study groups as a method to be academically successful. Then the researcher probed, "Do you get together with them after class to study, to prepare for a test and projects and stuff?" Danilo replied, "Right if I have a test, after they're done and go over the answers, such things, yeah."

Oscar believed that his success was due to being responsible with his schoolwork. He explained that, "A thing that has helped me is always being responsible with my stuff, always being on time and never procrastinate." He also emphasized that he is strong academically in both math and science.

David believed that his reading comprehension skills and his ability to guide himself has been instrumental to his success. He noted:

I think reading in general, improving my skills in reading. Reading comprehension is probably the most important thing in college because a lot of the time you're going to class, the professor is a guide, is a resource you can treat 
it as to what the person is going to teach you so reading is where you do most of your learning and even then the more I progress through my studies and I'm not looking towards like graduate school. Your own research and your own ability to read and understand that's like the key factor.

Demonstrating his self-regulation skills (Zimmerman, 2000), David also noted, "I've used the library, I've used like the counselor resources and I've used a little bit of their research labs..." Gregorio was also self-regulated because he said, "[I] do my homework, I study, [get] tutoring and ask questions."

Sofia believes that her effort has helped her succeed. She indicated:

My input. The effort that I put in my studying and taking time for me to study the lessons. To do good in the past and the present. You know, it's everything in my effort and also my mother. She helped me.

Exhibiting her self-regulated learning skills, Sofia also utilized the resources and guidance the college had available:

Oh yes. Yes. We use the Library a lot. Sometimes when I have to study, I just go right there to the Library and print out information. Um what else. Oh any problem I have I talk to my counselor, she helps me a lot. And what else. Oh and the teachers, I'm always the person that if I don't understand something, I talk to the teachers, so that too. Yes that's pretty much it.

\section{The Role of Friendship}

An important characteristic of students who persist until graduation is the amount of time, they have invested in the university culture by participating in extracurricular activities, becoming members of school clubs, and making new friends (Astin, 1975).

The participants spoke of how their friends shaped their lives as children, adolescents, and in college. Some of these friends supported them and helped them reach their goals, while others had a detrimental effect on their lives. The participants felt that 
often it was difficult to maintain high school friendships and interact with other people in college because of their work responsibilities and time constraints.

Rosa thinks that her friends unwittingly encouraged her to go to college because they were all competing against each other:

My friends, who were also kind of like my competition because we were also applying to the same colleges and kind of applying to the same scholarships, and you know, we all have the same aspirations, obviously to go to college. In that way, the encouragement, because they were my competition but not because they ever explicitly said, "I want you to go. You should go."

Gisela did not have a positive experience in high school either with the friends she made in the honors program called Cambridge. She responded:

I couldn't really get out because I wanted to be in Cambridge. So even if I didn't really like the people so much, I had to learn to like them or learn to just hang out with them and stuff. And I found that although they were fun to hang out with and stuff they weren't really people I could rely on and trust.

However, Karina's experience with her peers was different. She felt that they

were supportive in high school and are still supportive to this day:

Yes, I had a lot. There were many people who helped me to feel more comfortable, especially when I didn't want to get out of my comfort zone and just to stay by myself. At lunch, there were a lot of peers who would get close to me and talk to me and share. It's all these experiences, they will always make classes more comfortable.

As a traditional student, Rosa's experiences changed in college. She participated in activities and clubs, and interacted with her peers:

This week actually, I've been campaigning with my student government group and just been going up to students and just kind of motivating them to go vote, which our student government election [inaudible 00:46:58] next week. Also, I'm really, really involved with my church here in Gainesville. I found a really good church and I think the majority of my friend base comes from this church. I love 
my friends and I get involved with the church. Actually, tomorrow I'm scheduled to supervise the kids. I do that as well.

Then, what other thing I ... Actually, I didn't really get involved until last year and this year with activities. My freshman year and sophomore year, I didn't really do anything especially in my freshman year, I didn't do anything, like any school activities. But, in my sophomore year like I said, I worked in school. It took up so much of my time that I didn't really have time to devote to extra curriculars. But I think now because I am senior and I'm realizing that I'm going to graduate soon, I want to get involved and, you know, just meet as many people as I can. So, yeah.

When the researcher asked Rosa what friends she interacted with often, Rosa had

this to say:

Yes. My friend base, my group of girls that I see every week. I interact with my roommates even though they're just friends, kind of like strangers. But, I do interact with my roommates. Yesterday, I actually baked them cookies. There's people here at UF all around. There's like 55,000 students. There has to be someone I can interact with, you know? But yeah, I do have my group of friends and my classmates, even then, I'm really friendly with my classmates. We meet up to do homework like projects and stuff. So, yeah. I'm usually never alone.

When asked if he participated in any extracurricular activities, Rafael replied that

he is very active in a group that advocates for immigrants' rights:

I am very active with ... I've been for the last five years, there's been a college, it's not inherently college, but there's an organization for youth that was created by and it's led by, and it has been run by immigrant youth and allies for the advocacy of immigrants' rights that I've been active for the last five years and it's been a club many times at college, it was a club at Miami Dade, right now it's not a club officially but they are an extracurricular activity that are usually centered around colleges because a lot of the members are college aged folks.

As mentioned previously, some students simply interacted with their peers in college for the purpose of studying or barely interacted at all. For Oscar, the college experience was very isolating:

Well, it was very different from a regular high school. First day up, everyone was like in their business, like what they had to do, they were like that, they were not 
like ...it is a really different experience from high school. I just went to my class and then I got out. I don't know, it is so different.

Cristobal felt the same way about his interactions in college:

I only have one friend and we don't talk too much about other stuff. We just talk about the work. And we have like a group chat, and so all the class he's there like: "Do you need help with this? So there's this, this, this and this." Yeah, he works, too. He work from 4PM to 4AM, and he go to college at 8AM, so-

In some cases, the participants were able to maintain the friendship with their high school buddies, but it was often the case that their lives took separate turns because they were following different paths. In other cases, the participants made the conscious decision to end the friendship because it was detrimental to their life goals.

\section{Facing an Unknown Future}

College students like to think that their hard work and dedication will reap rewards in the future. Naturally, they hope that after graduating, they will be able to find the job of their dreams or be accepted into the graduate school of their choice. Reio (2007) talked about the vital role that taking risks has in learning and developing across the lifespan. For example, without taking the risk of stepping outside of one's comfort zone by taking college classes as an ESOL student, despite the uncertainty and fear of failure, optimal learning and development can be delayed indefinitely or deterred completely (Reio, 2007).

The participants shared with the researcher where they hoped to be in five years' time. The responses to this question are indicative not only of what the participants' long term plans are, but also provide some insight on their intent to persist. They replied: 
Rosa said, "I really wanted to get a master's degree now. The question is, should I get my master's degree here in the United States or should I go to Germany and do my master's degree?

Danilo asserted, "Hopefully I'll be finishing school and I'll be looking to move to a state or a country that fits my needs and personality and looking through settle my life down."

Mayra answered, "Maybe working, but Med school and work, I will say."

Karina articulated, "Five years from now, I see myself having a bachelor's degree already and probably working forward in my studies. Financially different, better. Getting to know more people in my network and extend it."

Oscar said "I look myself in five years from now and I graduated and working in a company for building towers, if I call it. Buildings. For making buildings. Seeing myself working on there."

David stated:

Five years from now, if everything works the way I want it, I should be working with the... I should be a clinical psychologist. That's not a concern for now, I learned as a counselor of mental health and I will be working with a population of like pretty much either schizophrenia or depressed anxiety people and helping them out and then probably starting a doctorate in neuroscience, which FIU is going to have to do some.

Charles disclosed, "Be an architect and have a family." 
Estefania said, "I hope to be graduated, working on my Master's, possibly even graduate with my Master's. Start working in my career and start a family. Get married and have kids."

Cristobal stated, "I will say that I will be in a big university, continuing my career. Probably working. It's like for sure 'cause I have to pay bills. And I'm not sure but I'll be probably living by myself.

Lorenzo revealed, "So I really can't tell what I'm going to be doing in five years, but I do see myself leaving south Florida and being somewhere else."

Gisela said, "I hope to be a graduate of UF and possibly working at an ad agency maybe in like New York or California. I have big dreams, but yeah, I hope to be doing what I love, which is like design and writing and selling.

Gregorio replied, "My future in five years... have my diploma, have good job, family, and a good man for my family.”

\section{Sofia disclosed:}

Oh, five years from now I will be working at a hospital and I'm happy. Probably already bought my house and just not having to worry about, oh I need to save money to pay the bills or to pay the lights or pay the water. And I will be living good. Not rich, but it will be good. Five years from now.

Rafael said, "I'll be 34, so the plan is to be graduated and practicing engineering by that time sounds old to graduate but that's the plan."

All of the participants were looking forward to their future and persisting until graduation. Not one of them said that they would consider dropping out. In fact, Rosa, 
Mayra, David, and Estefanía admitted encouragingly that they would like to begin working on advanced degrees in the future. In general, they wanted to achieve their dreams, but they also wanted to graduate so they could support themselves and "pay the bills," like Cristobal said. Gregorio, Charles, and Estefania also wanted to start a family in five years' time. Lorenzo, Danilo, and Rosa were not completely sure where they would be in the future because they thought about relocating to another city or country after graduation. All of the participants, without exception, hoped to enjoy an improved lifestyle due to their hard work and perseverance.

Finally, the participants offered some advice for future English Language Learners who would like to attend college:

Rafael advised, "Find any way shape or form to practice the language." Karina instructed:

I will say that if you want it that bad, you will get to do it. No matter if you [struggle financially, there's always family that will support you. There is always someone will encourage you to keep going. There's nothing impossible if you want to do it. Be open to learn. Be open to sometimes feel vulnerable and ask for help.

Estefanía counselled, "I would say not to be afraid and everything is possible. To study. Form themselves with people who can help them succeed and use their resources at school." Last, Charles warned, "Study a lot.... [and] always stay motivated."

When the participants were asked to advise English Language Learners who wished to go to college, some like Rafael were adamant that they practice their English as much as possible. Others like Estefanía and Charles advised them to study and work to 
achieve their goals. Estefanía summed it up best when she told them to not be afraid, that everything was possible, to keep company with people who could help them succeed, and

The participants were all aware that their futures could be planned to a certain extent, but they could be led in unexpected directions. They knew that at the heart of being successful it was necessary to be proactive and take risks in making your goals come to fruition. Like Karina advised, “... There's nothing impossible if you want to do it. Be open to learn. Be open to sometimes feel vulnerable and ask for help.

\section{Summary}

This chapter reported the findings of the qualitative data and the themes that were produced using the inductive method. In delving into the participants' experiences, the researcher found the themes of (1) motivation, (2) the pursuit of the American dream, (3) the struggle to persist in college, (4) the role of friendship, and (5) facing an unknown future upon graduation. The participants' stories relating to (1) support from family, teachers, and friends, (2) their role models who inspired them, (3) the challenges they faced in learning a new language and adapting to a new country, as well as (4) their college experiences and aspirations became the themes for this research. 


\section{CHAPTER V}

\section{DISCUSSION}

In this chapter, the findings will be discussed and how they fit in with the theoretical framework. That will be followed with the theoretical and practical implications of the research study; in other words, how can the knowledge gained from this study be applied theoretically and empirically. The limitations of the study will be discussed, which will be helpful not only in delineating what the limitations are but also providing insight into possibilities for researching areas not covered in this study. That leads to the final section, the recommendations for future research, which will suggest possible angles or topics that can add to the literature on adult education.

\section{Research Findings}

The theme of encouragement and motivation from families and teachers finds support in Tinto's theory of student departure. In Tinto's theory, he describes the importance of this support so that students can make the difficult transition from high school graduation to college. If on the contrary, "the orientation of the family or local peer group does not support, indeed opposes, participation in higher education, early separation and transition may be measurably more difficult" (Tinto, 1988, p. 444). The participants responded that they had felt supported by their families and teachers, and especially their parents. Some of the participants indicated that they had felt welcomed in the college community, even if it was a two-year college or commuter institution. Tinto also emphasized the importance of students feeling welcomed by the faculty and their peers when they made the transition into college (Tinto, 1988). 
In many cases, the inspiration felt by the participants was so strong, that they considered their parents and teachers role models. Role models is an essential part of Bandura's social cognitive theory, in which individuals learn through social interaction and imitation of people whom they admire. According to the participants, the role models in their lives were usually one of both parents or a favorite teacher who made a special impact on their lives. For instance, Sofia reminisced about how her mother would take her to the university when she was studying for her degree in dentistry. She believes that this inspiration is the reason why she is attending college now. Modeling can also take place in the form of instruction because some students felt that they learned how to perform certain tasks through observing or working on a project with assistance from their instructor. Cristobal believes that his architecture instructor helped him become better at his craft by focusing on the details of his architectural sketches.

The theme of the power of motivation in the pursuit of the seemingly elusive American Dream did not fit in with the theoretical frameworks discussed previously. Morales, Herrera, \& Murray (2011) describe how the "resiliency" factor determines whether these immigrants will succeed or not, especially if they are also undocumented. Garabino (1995) defined resiliency as "qualities that foster a process of successful adaptation and transformation despite risk and adversity" (p. 103). Morales et. al (2011) utilize Bonnie Bernard's (2004) framework on resiliency to describe the four internal factors and three external factors that determine resiliency. The internal factors are those factors inherent in the individual that are evidenced when the individual encounters hardships. These four internal factors are: “(a) social competence, (b) ability to solve problems, (c) autonomy, and (d) a sense of purpose" (Morales et. al, 2011, p. 7). External 
factors are considered those characteristics that constitute the family environment in which the individual developed resiliency. "The three external or environmental/familial factors that are said to be protective factors for students are (a) caring relationships, (b) high expectations, and (c) opportunities for participation and contribution" (Morales et. al., 2011, p. 7). Internal and external factors are said to work cooperatively to produce resiliency in challenging situations. The theoretical framework of resiliency fills a missing gap in the researcher's findings and explains why most of the participants were able to overcome hardships that would cause many others to drop out. To illustrate, Roberto described how his family helped him to persist by providing stability and a livelihood despite his undocumented status.

For the fourth theme, the participants told their stories about their difficulties in navigating the higher education system as first-generation college students, and this was due in great part to their status as first-generation Americans. Tinto provided some insight into the nontraditional student experience because he explained that his student departure theory did not work the same in different contexts. For example, he stated that commuter students initially have an easier time adapting to college because the familiarity of home remains the same. However, he explained that this could also be a disadvantage because sooner or later, the students would need to adapt to the college environment, and because they had never fully detached from their familiar environment, this process could be much more arduous. He also indicated that first-generation students find it particularly difficult because they may lack support to make the transition to the higher education experience (Tinto, 1983). Astin's theory of student involvement is an integral part of this theme because of the nature of being a nontraditional, first-generation 
student signifies that these students will not have the advantage of adapting fully to the college environment due to family, work, time, and budgetary constraints. Some of the participants voiced their regret in not being able to fully participate in college activities and spend time with friends due to these issues. Bandura's social cognitive theory and Zimmerman's self-regulating learning strategies both stem from self-efficacy, which is also related to Bernard's resiliency framework. Students who possess self-efficacy are resilient because they use self-regulating learning strategies. They believe they can succeed in uncharted territory because they have already successfully adapted to a new country; thus, they can be resourceful with time management and self-monitoring, and become more self-directed in their studies as described by Knowles's theory of andragogy.

The fourth theme of friendships and the role they play in the participants' lives is also related to Bandura's social cognitive theory, Astin's theory of student involvement, but especially to Tinto's theory of student departure. Tinto believed that students needed to distance themselves from family, friends, and the comfort of their home environment so that they could successfully transition to college. For some of the participants this was true, but not for all. Due to many of them being commuter students, they did not need to distance themselves from family and friends. Yet, many of them did not have time to spend with friends as they had been accustomed to in their high school days. Others were able to attend college or university with their friends and they helped each other academically and by providing moral support.

Finally, the fifth theme of uncertainty of the future and participants' expectations after graduation highlighted the need for the participants to be comfortable with risk- 
taking. According to Reio (2007), educational risk-taking entails changing your world view or schema. Educational risk-taking is "imaginative, inventive, uncertain, and goes beyond the ordinary and predictable in ways that can titillate, excite, and very often frighten.... oriented toward some uncertain and wished-for future" (Lightfoot, 1997, p. 1). Bandura's social cognitive theory by the same token is inextricably tied to risk-taking and how the relationships individuals develop throughout their lives, first within the family, then the school, higher education, and beyond provide the impetus they need to dare to succeed.

\section{Theoretical Implications}

This study has theoretical implications for the adult education field. First, consider that Bandura (1997), Tinto (1993), Astin (1985), and Zimmerman (2000) developed their theories with more traditional students in mind. Thus, by utilizing firstgeneration college students whose English is a second language, the researcher broadened the scope of these theories by using them to interpret and make sense of the data derived from this study of persistence among a group of underserved, nontraditional students or students with nontraditional characteristics. This population faced a series of challenges that the traditional, native-born population typically does not; for example, they had a language barrier to overcome in addition to learning how to navigate the world of higher education on their own without parental guidance. This research enriches what we already knew about the theories in that they were useful in making some sense of the disparate findings, despite working with this unique group of learners. For example, finding that role models really matter regarding persisting in school with this underserved population is powerful support for Bandura's social cognitive theory. Likewise, finding 
that the participants had difficulties navigating the higher education system was consistent with Tinto and Astin's theoretical work. The powerful role of motivation is deeply intertwined in Bandura's social cognitive theory as it relates to self-efficacy. In contrast, the findings also suggest that Tinto's theory might be enriched further by integrating pursuit of the American Dream as a motivational variable into his theoretical models. The finding that self-regulated learning skill (e.g., note taking, planning) was acknowledged as being significant to the participants in their efforts to perform and persist strongly supported Zimmerman's theory, suggesting that his theoretical work could inform future research with nontraditional learners. Finally, uncertainty about the future, the last theme, was relevant to the participants because it highlighted the notion that risk taking is an important part of learning, performing and persisting in an academic setting, which supports Bandura's social cognitive theory and Reio's (2007) idea that intellectual risk taking is a vital part of learning. This research extends Reio's risk taking ideas in that risk taking is not only linked to uncertainty, learning and developing, but also extends to persistence in an academic setting. Thus, intellectual risk taking is a positive thing in academic settings in that taking risks exposes one to new learning opportunities. However, risk taking can be negative in that it is associated also with the possibility of being ostracized for even going to school in the first place. Working class families in Hispanic culture eschew academic endeavors in favor of working to support the family in their businesses and at home. The participants in this research knew they were risking being ostracized from the moment they announced their intentions to go to school, yet they took the risk to do something positive with their lives. Continually taking risks for the sake of learning, attaining a degree, and thereby improving their chances for 
success was a strong motivational component of persisting for the participants, despite all the obstacles.

Unlike the prior four theories (Bandura, Tinto, Astin, and Zimmerman), Knowles' (1990) andragogical theory does honor the nontraditional adult learner, but it has been used sparingly to work with underserved populations. Interestingly, Knowles' readiness to learn, learner experience, pragmatic orientation to learning, and self-directedness tenets were important considerations for this group of adult learners, but the need to know why did not emerge from the data. It may be that it was not natural for these Hispanics learners to ask why they needed to learn something in that it would be considered inappropriate behavior. This dynamic is common with learners in Asian, Middle-Eastern, African, European, and Central/South American cultures (Cross, 1992). Further, the motivation of each learner was especially high, but their motivations tended to be more extrinsic (e.g., I want to get a better job), rather than intrinsic as Knowles suggested. It may be that this may be more a reflection of the ELL learners in this research, who tended to be quite goal-directed toward degree attainment instead of learning for the sake of learning that adult learning endeavors tend to entail (e.g., take a French cooking course to satisfy one's curiosity).

Moreover, because these participants were mostly commuter students, they had to be even more self-directed and motivated than students who resided in college. Many of them lacked the social interaction and participation in extracurricular activities that would have assisted them in feeling like a part of their institution's community, and according to Astin (1985), this could be a hindrance for persistence. However, despite their lacking in this area, the researcher found that the participants were determined to persist, so perhaps 
this theory could be modified further with regards to nontraditional learners or learners with nontraditional characteristics like the ones investigated in this study. One way to accomplish this is through going beyond Astin's narrow views about what constitutes and facilitates or impedes engagement and acknowledging that culture can influence the choices to become more involved in school. It may be that Hispanic students like those in this research, many of whom were first-generation college students, had no idea that involvement in school was recommended and protective and how to do so remained unclear at best. Hispanic culture does necessarily embrace becoming involved in school at the expense of remaining involved with the family. Hence, Astin's theory could use refinement with regards to how culture can enhance or inhibit school involvement, particularly with Hispanics.

\section{Implications for Practice}

The findings also highlighted areas where adult education practice could be informed. The participants in this study benefitted much from observing, imitating, and modeling parent, teacher, and professor behavior. Bandura's (1997) social cognitive theory, which emphasizes that people learn through observation, imitation, and modeling could be put to practical use in instructional methodology, curriculum development, and the use of mentors as role models. With instructional methodology, the students can be taught through observation of the instructor who is modeling the behavior that students need to learn. After observation of that behavior, the students can then imitate it on their own. This is known as the "I Do, We Do, and You Do" Gradual Release of Responsibility Model of classroom instruction (Pearson \& Gallagher, 1983). This is widely used in teaching students in K-12 settings. Still, it might be beneficial for higher 
education instructors to keep this in model mind when designing instruction with nontraditional adult students, like the ELL students in this research, because adult learners tend to respond well to instruction where they observe, and then imitate and especially practice the behavior on their own (Bandura, 1998). The experience of practicing the behavior allows the adult learner to draw upon their own prior experiences to make personal meaning of the task and therefore learn (Knowles, 1990). The curricula of college courses could be made more adult learner-friendly by taking this into account, and offer students many opportunities to observe, imitate, and practice the behaviors that professors expect to be assimilated.

The participants in this research benefitted from mentoring experiences with peers. The use of peer mentors could be emphasized more in higher education, especially for incoming Freshman students. These mentors could be assigned to work with them at least for two semesters, and assist with financial aid, helping them access tutoring, and simply providing them guidance. College advisors would also be available to provide support with remediation, and referrals for mental health counseling.

In keeping with Zimmerman's (2000) self-regulating learning strategies and Knowles' (1990) principles of self-directedness, Freshman Orientation classes could include strategies for planning and self-monitoring which are extremely helpful to students attending college for the first time, especially ELL students who sometimes lack the preparation for college-level academic rigor that their peers often enjoy. Workshops could be offered on a regular basis, at least every semester, which could provide strategies to avoid procrastination, manage time wisely, and monitor writing skills and math skills. 
The current research, as Tinto's (1993) theory of student departure suggested, revealed that the students could benefit much from minimizing obstacles that hinder students from progressing in their higher education studies. For example, navigating the labyrinth of the college system was especially troubling for the first-generation college students in this study. Minimizing and eliminating obstacles or institutional barriers in the higher education system is of upmost importance (Cross, 1992). First-generation students feel very frustrated when they do not know where to go or whom to approach for financial aid, registration, and advisement for classes needed for their majors. Due to being commuter students who often study part-time and hold outside employment, they have little time to waste taking classes that they do not need, or worse, dropping classes because of the lack of financial resources. Situations such as this overwhelm students and all-too--often lead students to withdraw from college. In addition, it is important that college professors be provided with workshops on teaching methodology to work specifically with nontraditional students or students with nontraditional characteristics. Too many times, students feel lost in classes when the curriculum, syllabus, or lesson is poorly executed. It is not enough for the professors to be experts in their subject matter; they need to be able to reach the students. Institutions of higher learning clearly risk losing their students when professors do not make instruction a priority.

Some of the participants did engage in and benefit from extra-curricular activities. If Astin's (1985) theory of student involvement is to be taken into account, it would be wise to help the nontraditional students to involve themselves more into college culture. For those nontraditional students or those with nontraditional characteristics who have families, they can provide family-friendly activities for these students, so they do not 
have to feel that they have to choose between their social lives and their families. These activities could be attuned to generational differences and the Hispanic community in general. Reaching out to minority students who do not speak the language is beneficial for everyone. The students not only feel that they are part of their new college community and thus socialized into college life; it is also easier to become more proficient in the English language because they are interacting with their peers.

\section{Limitations and Recommendations for Future Research}

While this study's findings have theoretical and practical implications, there are still limitations that need to be discussed. All of the fourteen participants in this study needed to meet the following criteria: be 18-years-of-age and over, Hispanic, English language learner, lived in South Florida, and enrolled in college taking classes in their respective majors. Due to adhering to these selection criteria and the relatively small sample size, it would be implausible and inappropriate to generalize these results to a larger population. Future research should be designed to first replicate this study in other geographic areas with a large Hispanic ELL population outside of south Florida to see if the same five themes that were discovered in this study emerge from this different population. In addition, it may be that data saturation around the five themes may occur either earlier or later or not at all with new research samples, but only additional research will tell. Another way to extend this research would be utilizing another immigrant population, such as the Haitian-Creole and Asian populations, to see if the insights gained from the current research are consistent as well.

For a study to be generalizable to a larger population, at least 150 participants need to be included in a study (Creswell, 2008). Of course, this does not mean that the 
information gleaned from this study of 14 participants is not useful; it simply is not generalizable. The benefit of having conducted a phenomenological study is that the researcher was able to glean a richer, more detailed sense of how this group of first-year Hispanic ELL students experienced their first-year of college than if a survey approach would have been utilized. From these experiences, the researcher was able to obtain insights into how and why these experiences were linked to persisting in college. Still, conducting qualitative research with large numbers of participants remains a possible means to increase generalizability (Creswell, 2008). Acknowledging that such a qualitative study could be time and cost prohibitive, it would be quite useful for teasing out further the insights gained from this research and generalizing beyond it. In turn, this new qualitative information would be very useful for further theory-building efforts (Reio, 2011).

Another approach to increase generalizability would be to first develop a new instrument based on the five themes to measure perceived likelihood to persist in college. The thinking is that if one indicates higher positive scores on the new measure, they will be more likely to persist in school. Instrument development would include generating a pool of items first to measure each of the six themes. Next, one would analyze the items for content validity (with experts in the fields of adult and higher education). Third, a pilot study with a focus group would be implemented to determine clarity of instructions and items, and finally conducting a study or series of studies ( $N_{\mathrm{s}} \geq 150$ in each) where a battery of instruments that includes the new measure would be included to get discriminant, convergent, and construct validity evidence (Creswell, 2008). With sufficient evidence of construct validity with the new measure, it can be used 
subsequently in new large samples to predict actual persistence in college. The new findings could help determine which of the six themes are most salient for Hispanic ELLs and because of the large sample size, would be more generalizable.

Noteworthy was how pursuit of the American dream, not typically addressed in adult and higher education studies, motivated the participants to persist in college. New research could be designed to tease out this notion further. Case study research could be used with individuals highly motivated to pursue the American dream to get a better sense of how and why this motivates them so.

This study also eliminated those students who were not yet proficient in English, so the findings may have differed if students were included that were not English proficient. Future research should be conducted to ascertain if the findings would diverge based on differing levels of English proficiency.

Finally, because all of the participants were currently enrolled in their major classes in college, they indeed felt positive about their likelihood of persistence until graduation. In this case, the major hurdles of being accepted into college, taking remedial classes, and completing their ESOL classes may have been largely behind them, which may have influenced perceptions of their collegiate experience. New research should be designed that compares the likelihood of persistence of those who have overcome these three major hurdles versus those who have not.

\section{Summary}

In Chapter 5, the researcher analyzed the responses to the semi-structured interview questions by viewing them through the lenses of Bandura's (1997), Tinto's (1993), Astin's (1985), Knowles's (1990), and Zimmerman's (2000) theories. The 
researcher found a correspondence between the participants' experiences and each of these theories to some degree. However, the researcher also noted how all of the participants were either nontraditional students or students with nontraditional characteristics and even first-generation, yet some parts of these theories did not apply to them (e.g., need to know why did not emerge from the data which is in contrast to Knowles's andragogical theory). The theoretical and practical implications of this research, how they could be utilized to expand on the literature as well as the practical applications in adult education contexts were examined. Finally, the researcher limitations and recommendations for further qualitative and quantitative research were discussed. 


\section{References}

Adams, C. \& Van Manen, M. A., (2017). Teaching phenomenological research and writing, Qualitative Health Research, 27, 780-791.

Ajzen, I. (2002). Perceived behavioral control, self-efficacy, locus of control, and the theory of planned behavior. Journal of Applied Social Psychology, 32, 665-683.

Ajzen, I., Czasch, C. \& Flood, M.G. (2009). From intentions to behavior: Implementation intention, commitment, and conscientiousness. Journal of Applied Social Psychology, 39, 1356-1372.

Almon, C. (2015). College persistence and engagement in light of a mature English language learner (ELL) student's voice. Community College Journal of Research and Practice, 39, 461-472.

Arana, R., Castaneda-Sound, C., Blanchard, S. \& Aguilar, T. (2011). Indicators of persistence for Hispanic undergraduate achievement: Toward an ecological model. Journal of Hispanic Higher Education, 10, 237-251.

Artino Jr, A. R. (2005). Review of the Motivated Strategies for Learning Questionnaire. Online Submission.

Astin, A.W. (1975). Preventing students from dropping out. San Francisco: Jossey Bass

Astin, A.W. (1993). What matters in college. Liberal Education, 79(4), 4-15.

Bandura, A. (1997). Self-efficacy: The exercise of control. New York: W.H. Freeman and Company.

Bandura, A. (1999). Social cognitive theory: An agentic perspective. Asian Journal of Social Psychology, 2, 21-41.

Bandura, A. (2012). On the functional properties of perceived self-efficacy revisited. Journal of Management, 38, 9-44.

Barros-Nock, M. (2017). The effects of DACA in young migrant's professional careers and emotions. Estudios fronterizos, 18(37), 131-148.

Baum, S. \& Flores, S. M. (2011). Higher education and children in immigrant families. Future of Children, 21, 171-193.

Berger, J. B. \& Milem, J .F. (1999). The role of student involvement and perceptions of integration in a causal model of student persistence. Research in Higher Education, 40, 641-664. 
Benard, B. (2004). Resiliency: What we have learned. San Francisco: WestEd.

Bliss, L. B. \& Sandiford, J. B. (2003). The effects of institutional culture on study strategies of Hispanic students as measured by the inventario de comportamiento de estudio, the Spanish version of the study behavior inventory. Journal of Hispanic Higher Education, 2, 203-220.

Bogdan, R. C. \& Biklen, S. K. (2007). Qualitative research for education: An introduction to theories and methods ( $5^{\text {th }}$ ed.). Boston, MA: Allyn \& Bacon

Caffarella, R., \& Merriam, S. B. (2000). Linking the individual learner to the context of adult learning. In A. Wilson \& E. Hayes (Eds.), Handbook of Adult and Continuing Education (pp. 55-70). San Francisco, CA: Jossey-Bass.

Cadenas, G. A., Bernstein, B. L., \& Tracey, T. J. G. (2018). Critical consciousness and intent to persist through college and DACA and U.S. citizen students: The role of immigration, status, race, and ethnicity. Cultural Psychology and Ethnic Minority Psychology, 24, 564-575.

Carter, D.F. (2006). Key issues in the persistence of underrepresented minority students. New Directions for Institutional Research, 130, 33-46.

Chang, J. C. (2005). Faculty-student interaction at the community college: A focus on students of color. Research in Higher Education, 46(7), 769-802.

Chun, H., Marin, M. R., Schwartz, J. P., Pham, A. (2016). Psychosociocultural structural model of college success among Latina/o students in Hispanic-serving institutions. Journal of Diversity in Higher Education, 9, 385-400.

Coffman, S. (2011). A social constructionist view of issues confronting first-generation college students. New Directions for Teaching and Learning, 127, 81-90.

Collier, P. J. \& Morgan, D. L. (2008). "Is that paper really due today?”: Differences in first-generation and traditional college students' understandings of faculty expectations. Higher Education, 55, 425-446.

Coley, R. J. (2000). The American community college turns 100: A look at its student programs, and prospects, Educational Testing Services, Princeton, NJ (ED 441 $553)$.

Conway, K. M. (2010). Educational aspirations in an urban community college: Differences between immigrants and native student groups. Community College Review, 37, 209-242.

Creswell, J. W. (2009). Research design: Quantitative, qualitative, and mixed methods approaches. $\left(3^{\text {rd }}\right.$ ed). New York: Sage Publications. 
Creswell, J. W. \& Miller, D. L. (2000). Determining validity in qualitative inquiry. Theory into Practice, 39, 124-130.

Cross, K. P. (1992). Adults as learners: Increasing participation and facilitating learning. San Francisco: Jossey-Bass.

Damewood, A. M. (2016). Current trends in higher education technology: Simulation. Tech Trends, 60: 268-271.

De La Cruz, Y. (2008). Who mentors Hispanic language learners? Journal of Hispanic Higher Education, 7, 31-42.

DeVon, H., Block, M., Moyle-Wright, P., Ernst, D., Hayden, S., Lazzara, D., Savoy, S., Kostas- Polston, E. (2007). A psychometric toolbox for testing validity and reliability. Journal of Nursing Scholarship, 39, 155-164.

D’Lima, G. M., Winsler, A., \& Kitsantantas, A. (2014). Ethnic and gender differences in first-year college students' goal orientation, self-efficacy, and extrinsic and intrinsic motivation. The Journal of Educational Research, 107, 341-356

Duque, L. C. (2014). A framework for analyzing higher education performance: students' satisfaction, perceived learning outcomes, and dropout intentions. Total Quality Management, 25, 1-21.

Englander, M. (2012). The interview: Data collection in descriptive phenomenological human scientific research. Journal of Phenomenological Psychology, 43, 13-35.

Espinoza, A. (2013). The college experiences of first-generation college Latino students in engineering. Journal of Latino/Latin American Studies, 5(2), 71-84

Feria, J., Valcke, M., \& Schuyten, G. (2010). Judgments of self-perceived academic competence and their differential impact on students' achievement motivation, learning approach, and academic performance. European Journal of Psychology of Education, 25, 519-536

Fiebig, J. N. et. al. (2010). Hispanic community college students: Acculturation, family support, Perceived educational barriers, and vocational planning. Community College Journal of Research and Practice, 34, 848-864.

Garabino, J. (1995). Raising children in a socially toxic environment. San Francisco: Jossey-Bass

Garza, K. K., Bain, C. F., \& Kupcynski, L. (2014). Resiliency, self-efficacy, and persistence in higher education. Research in Higher Education Journal, 26, 1-19. 
Gayman, M. D., Cislo, A. M., \& Ueno, K. (2014). SES and race-ethnic differences in the stress-buffering effects of coping resources among young adults. Ethnicity \& Health, 19, 198-216.

Gilstrap, D. L. (2013). Why do we teach? Adult learning theory in professional standards as a basis for curriculum development. College \& Research Libraries, 501-518.

Gollwitzer, P. M. (1999), Implementation intentions: Strong effects of simple plans. American Psychologist, 54, 493-503.

Goetz, J. P., \& LeCompte, M. D. 1984. Ethnography and qualitative designs in ethnographic research. New York: Academic Press.

Gonzalez, R. G. (2010). Ethnic identity at a majority Hispanic-serving institution. Journal of Latinos and Education, 9, 284-302.

Gonzalez, L. M., Stein, G. L., \& Huq, N. (2012). The influence of cultural identity and perceived barriers on college-going beliefs and aspirations of Latino youth in emerging immigrant communities. The Journal of Behavioral Sciences, 35, $103-$ 120.

Gordon, K. (1996). Resilient Hispanic youths' self-concept and motivational patterns. Hispanic Journal of Behavioral Sciences, 18, 63-73.

Healy, M., \& Perry, C. (2000). Comprehensive criteria to judge validity and reliability of qualitative research within the realism paradigm. Qualitative market research: An International Journal, 3, 118-126.

Howell, D. C. (2007). Statistical methods for psychology $\left(7^{\text {th }}\right.$ ed.). Belmont, CA: Duxbury Press.

Hu, H. \& Driscoll, M. P. (2013). Self-regulation in e-learning environments: A remedy for community college? Educational Technology \& Society, 16, 171-184.

Huie, F .C., Winsler, A., \& Kitsantas, A. (2012). Employment and first-year college achievement: The role of self-regulation and motivation. Journal of Education and Work, 27, 110-135.

Hyland-Russell, T., \& Syrnyk, C. (2015). Challenging change: Transformative education for economically disadvantaged adult learners. International Journal of Lifelong Education, 34, 514-529.

Iran-Nejad, A. (1990). Active and dynamic self-regulation of learning process. Review of Educational Research, 60, 537-602. 
Iran-Nejad, A., \& Chissom, B. S. (1992). Contributions of active and dynamic selfregulation to learning. Innovative Higher Education, 22, 125-136.

Ishitani, T.T. (2006). Studying attrition and degree completion behavior among firstgeneration college students in the United States. The Journal of Higher Education, 77, 861-885.

Jarvis, P. (2010). Adult education and lifelong learning: Theory and practice ( $4^{\text {th }}$ ed.), New York: Routledge.

John, W. S., \& Johnson, P. (2000). The pros and cons of data analysis software for qualitative research. Journal of Nursing Scholarship, 32, 393-397.

Kenner, C., \& Weinerman, J. (2011). Adult learning theory: Applications to nontraditional college students. Journal of College Reading and Learning, 41, 87-96.

Kesici, S., \& Erdogan, A. (2009). Predicting college students' mathematics anxiety by motivational beliefs and self-regulated learning strategies. College Student Journal, 43, 631.

Kim, S., Chang, M., Singh, K., \& Allen, K. R. (2015). Patterns and factors of high school dropout risks of racial and linguistic groups. Journal of Education for Students Placed at Risk, 20, 336-351.

Kim, Y., \& Park, S. Y. (2009). Reverse acculturation: A new cultural phenomenon examined through an emerging wedding practice of Korean Americans in the United States. Family and Consumer Sciences Research Journal, 37, 359-375.

Kitsantas, A., Winsler, A., \& Huie, F. (2008). Self-regulation and ability predictors of academic success during college: A predictive validity study. Journal of Advanced Academics, 20, 42-68.

Knowles, M. (1977). Adult learning processes: Pedagogy and andragogy. Religious Education, 72, 202-211.

Knowles, M. S. (1980). The modern practice of adult education: From pedagogy to andragogy (Revised and updated). Cambridge: New York.

Knowles, M. (1990). The adult learner: A neglected species. (4 $4^{\text {th }}$ ed.). Houston, TX: Gulf Publishing Co.

Knowles, M., Holton, E. F., \& Swanson, R. A. (1998). The adult learner: The definitive classic in adult education and human resource development. ( $5^{\text {th }}$ ed.). Houston, TX: Gulf Publishing Co. 
Liao, H. A., Ferdenzi, A. C., \& Edlin, M. (2012). Motivation, self-regulated learning efficacy, and academic achievement among international and domestic students at an urban community college: A comparison. Community College Enterprise, 18, 9-38.

Lightfoot, C. (1997). The culture of adolescent risk-taking. New York: The Guilford Press.

McCall, R. C., Padron, K., \& Andrews, C. (2018). Evidence-based instructional strategies: A review of the literature. Codex, 4, 29-47.

McCutcheon, G. (1992). Facilitating teacher personal theorizing. In Ross, E.W., Cornett, J.W., and McCutcheon, G. (eds.), Teacher personal theorizing; Connecting curriculum practice, theory, and research, State University of New York Press, Albany, NY.

Meyer, D. C., \& Avery, A. M. (2008) Excel as a qualitative data analysis tool. Field Methods Online First, 20, 1-22.

Milem, J. F., \& Berger, J. B. (1997). A modified model of college student persistence: Exploring the relationship between Astin's theory of involvement and Tinto's theory of student departure. Journal of College Student Development, 38, 387400 .

Moilanen, K. L. \& Raffaelli, M. (2010). Support and conflict in ethnically diverse young adults' relationships with parents and friends. International Journal of Behavioral Development, 34, 46-52.

Morales, A., Herrera, S., \& Murry, K. (2011). Navigating the waves of social and political capriciousness: Inspiring perspectives from DREAM-Eligible immigrant students. Journal of Hispanic Higher Education, 10, 266-283.

Nakajima, M.A., Dembo, M. H., \& Mossler, R. (2012). Student persistence in community colleges. Community College Journal of Research and Practice, 36, 591-613.

Nandagopal,K. \& Ericsson, K. A. (2012). An expert performance approach to the study of individual differences in self -regulated activities in upper-level college students. Learning and Individual Differences, 22, 597-609.

Pajares, F. (1996). Self-efficacy belief in academic settings. Review of Educational Research, 66, 543-578.

Pascarella, E. T., \& Terenzini, P. T. (1980). Predicting freshman persistence and voluntary dropout decisions from a theoretical model. The Journal of Higher Education, 21, 60-75. 
Pearson, P.D., \& Gallagher, M.C. (1983). The instruction of reading comprehension. Contemporary Educational Psychology, 8, 317-344.

Pintrich, P. R. (2002). The role of metacognitive knowledge in learning, teaching, and assessing. Theory into Practice, 41, 219-225.

Rance-Roney, J. (2011). ELLs: What's the endgame? Educational Leadership, 68(7), 7478.

Reeves, T.D. \& Stich, A.E. (2011). Tackling suboptimal bachelor's degree completion rates through training in self-regulated learning (SRL). Innovative Higher Education, 36, 3-17.

Reio, T.G. (2007). Exploring the links between adult education and human resource development: Learning, risk-taking, and democratic discourse. New Horizons in Adult Education and Human Resource Development, 21, 5-11.

Reio, T. G. (2011). On stimulating curiosity and taking intellectual risks. Human Resource Development Review, 10, 3-5.

Robbins, S. B., Lauver, K., Le, H., Davis, D., Langley, R., \& Carlstrom, A. (2004). Do psychosocial skills and study skill factors predict college outcomes? A metaanalysis. Psychological Bulletin, 130, 261-288.

Rubin, H.J. \& Rubin, I.S. (2012). Qualitative interviewing: The art of hearing data $\left(3^{\text {rd }}\right.$ ed.). Los Angeles, CA: Sage Publications.

Schapiro, S. \& Livingston, J. A. (2000). Dynamic self-regulation: The driving force behind academic achievement. Innovative Higher Education, 25, 23-55.

Schwartz, S., Benet-Martinez, V., Knight, G.P., Unger, J.B., Zamboanga, B.L., Des Rosiers, S.E., Stephens, D.P., Huang, S., \& Szapoczanik, J. (2014). Effects of language of assessment on the measurement of acculturation: Measurement equivalence and cultural frame switching. Psychological Assessment, 26, 100-114

Schunk, D.H. (1989). Self-efficacy and cognitive achievement: Implications for student learning problems. Journal of Learning Disabilities, 22, 14-22.

Siemons, R., Raymond-Flesh, M., Auerswald, C.L., \& Brindis, C.D. (2017). Coming of age on the margins: Mental health and wellbeing among Latino immigrant young adults eligible for Deferred Action for Arrivals (DACA). Immigrant Minority Health, 19, 543-551.

Status of Current DACA Litigation. (2018, April 24). Retrieved May 2, 2018, from https://www.nilc.org/issues/daca/status-current-daca-litigation/ 
Stepick, A., Grenier, G., Castro, M., \& Dunn, M. (2003). This land is our land: Immigrants and power in Miami. Berkeley: University of California Press.

Thibodeaux, J. et. al. (2017). First-year college students' time use: Relations with selfregulation and GPA. Journal of Advanced Academics, 28, 5-27.

Tight, M. (2002). Key concepts in adult education and training. ( $2^{\text {nd }}$ ed.). New York: Routledge Falmer.

Tinto, V. (1975). Dropout from higher education: A theoretical synthesis of recent research. Review of Educational Research, 45, 89-125

Tinto, V. (1988). Stages of student departure: Reflections on the longitudinal character of student leaving. The Journal of Higher Education, 59, 438-455.

Torres, J.B., \& Solberg, V.S. (2001). Role of self-efficacy, stress, social integration, and family support in Latino college student persistence and health. Journal of Vocational Behavior, 59, 53-63.

Tovar, E. (2015). The role of faculty, counselors, and support programs on Latino/a community college students' success and intent to persist. Community College Review, 43, 46-71.

Tracy, S. J. (2010). Qualitative quality: Eight "big-tent" criteria for excellent qualitative research. Qualitative Inquiry, 16, 837-851.

Treviño, N. M. \& DeFreitas, S. C. (2014). The route between intrinsic motivation and academic achievement for first-generation college students. Social Psychology of Education, 17, 293-306.

Tuckman, B.W. (1972). Conducting educational research. New York: Harcourt Brace Jovanovich, Inc.

Valle, A., et. al. (2003). Cognitive, motivational, and volitional dimensions of learning. An empirical test of a hypothetical model. Research in Higher Education, 44, $557-580$.

Vassiliou, J. (2011). Improved outcomes with computer-assisted instruction in mathematics and English language skills for Hispanic students in need of remedial education at Miami Dade College, Florida. Community College Journal of Research and Practice, 35, 191- 201.

Vega, D. (2016). "Why not me?" College enrollment and persistence of high-achieving first-generation Latino college students. School Psychology Forum: Research in Practice, 10, 307-320. 
Walters, J. (2017). What is DACA and who are the Dreamers? (2017, September 24). Retrieved May 2, 2018 from https://www.theguardian.com/usnews/2017/sep/04/donald-trump-what-is-daca-dreamers

Wang, V., \& Hansman, C.A. (2017). Pedagogy and andragogy in higher education. In Wang,V. (Ed.), Theory and practice of adult and higher education. (pp. 87-111) Charlotte, NC: Information Age Publishing.

White, K. R. (1982). The relation between socioeconomic status and academic achievement. Psychological Bulletin, 91, 461-481.

Zajacova, A. Lynch, S.M. \& Espenshade, T.J. (2005). Self-efficacy, stress, and academic success in college. Research in Higher Education, 46, 677-706.

Zalaquett, C. P. (2006). Study of successful Latina/o students. Journal of Hispanic Higher Education, 5, 35-47.

Zimmerman, B.J. (2000). Self-efficacy: An essential motive to learn. Contemporary Educational Psychology, 25, 82-91.

Zimmerman, B. 2008. Investigating self-regulation and motivation: Historical background, methodological developments, and future prospects.

AmericanEducational Research Journal 45, no. 1: 166-83. 


\section{Appendix A}

Interview Protocol

\section{Background Information}

- Tell me a little bit about yourself.

1. How old were you when you came to Miami, and what were the reasons that brought you here?

2. Did you have any family members living here already who helped you with your transition to Miami?

- Tell me about your family's school experience in country here)

1. What was the highest level of schooling your mother achieved?

2. What was the highest level of schooling your father achieved?

3. What was the highest level of schooling that you achieved in your country?

4. Did you intend to attend college in your country?

\section{School in Miami}

1. What school did you attend and what can you tell me about your experiences there?

2. Did you have any friends or teachers that helped you to feel more comfortable in school?

3. Did you speak any English when you arrived?

4. Were you taking regular English classes before you graduated from high school?

Tell me about your experiences in college learning English.

1. How old were you when you started college?

2. What ESOL Level were you when you started college?

3. Were you a full-time or a part-time student? 
4. Were you working full-time or part-time when you first started college?

5. What were your intentions when you started college?

6. Describe how you felt when you first started attending college?

7. How long did it take you to finish your EAP (English for Academic Purposes) or ESOL classes?

- Tell me about your experiences in college when you began your major studies.

1. Have your intentions changed or have they remained the same?

2. Were you able to start immediately with your major classes?

3. Did anything in your life change at this point, like your employment or your family situation?

4. How would you describe your transition after completing your ESOL classes?

5. Did you feel that they prepared you for the classes that you are taking now?

6. Do you intend to finish your studies? If so, when?

\section{Factors that Have Contributed to Self-Efficacy and Self-Regulation}

- Think about your college experience so far, and what has contributed to your success.

1. Do you feel that you have the necessary academic skills to complete your major?

2. What do you consider your academic strengths?

3. What do you consider you academic weaknesses? How do you feel they can be improved?

4. Has any instructor used any strategy that you feel has particularly helped you?

5. Are there any strategies that you have used in the past or present to help you study or learn the material better? If so what are they?

6. What people have you met in college who have helped you?

7. Do you participate in any college activity outside of your studies? 
8. Do you have friends that you interact with often?

9. Were there any obstacles in the past or present that have made it difficult to continue in your studies?

\section{Closing Questions}

- Based on your experiences, what advice would you give to an English Language Learner who wanted to attend college?

- Describe what your future will be like five years from now.

- Is there information that I have not asked that you felt has contributed to your academic experience? 


\section{Appendix B \\ List of Codes \\ Themes, Codes, and Subcodes}

\section{Personal Background}

\section{Arrival to the U.S.}

When Arrived at the U.S.

\section{Reason/s for immigration to U.S.}

Search for a better standard of living

Search for a better education

Search for political freedom

Pursuit of the American Dream

\section{Country of Origin}

Situation in Native Country

Bad Economic Situation

Limited Educational Options

\section{Born in the U.S., But Did Not Speak English When Participant Went to School}

How Were Educational Opportunities Similar and Different from Foreign-Born Students

\section{Who Helped with the Transition to U.S.}

Relatives

Friends

How Did this Help Make a Difference?

Legal Status in the U.S. in the Present

Documented

Undocumented

\section{Repercussions of Being Undocumented}

Pay International Rates for College

Have to Work Full-Time

Study Part-Time

Fear of Deportation

\section{Educational Experiences in the U.S.}

\section{Elementary}

Didn't Speak the Language

ESOL Level When Began School

Bullied by classmates

Friends Who Helped

Teachers Who Helped 


\section{Secondary}

Didn't Speak the Language

ESOL Level When Began School

Bullied by classmates

Friends Who Helped

Teachers Who Helped

\section{Higher Education}

\section{Type of Institution}

College

University

\section{Living Situation}

Live On-Campus

Independently Off-Campus

Live with Parents

Challenges in Higher Education

Applying for Financial Aid

Not receiving support

Feeling Isolated

English Language Barrier

Not Being Able to Take Advantage of College Resources

\section{Resiliency to Overcome Challenges}

\section{Motivation to Succeed}

Who motivated them?

Role models

What motivated them?

Intrinsic motivation

Extrinsic motivation

\section{College Resources}

Advisement

Library

Tutoring

\section{Faculty/Student Interaction}

Participates in Class

Goes to Office Hours

Feels Comfortable Asking for Help

Academic Strengths

Reading Comprehension 
Writing

Mathematical

Organizational

\author{
Academic Weaknesses \\ Reading Comprehension \\ Writing \\ Lack of Mastery in English \\ Mathematical \\ Organizational \\ Procrastination
}

Extracurricular Activities

Participated or Did Not Participate

Type of Activity

School-Related

Political

Religious

\title{
Reasons for Not Participating
}

Not Enough Time

Family Responsibilities

Work Responsibilities

Persistence

Future Plans After Graduation

Intent to Persist Until Graduation 


\section{Appendix C}

\section{Researcher Journal and Field Notes}

\section{How I Chose My Topic}

When I was deciding on a topic for my dissertation, I knew that I had to write about motivation, how to succeed, and education. Having been an ESOL teacher and instructor for many years, I would always wonder why some students would fall between the cracks and others had it in them to persist until college graduation. I decided that this topic needed further study and research because I observed that too many former students of mine would tell me that they wished to continue their studies after high school, but I would be working minimum wage jobs a few years later after graduation. Some of these students had expressed that they wanted to pursue graduate degrees like medicine and law, but were not able to go to college due to their financial situation, lack of family support, not knowing how to navigate the college system, and even the feeling of not being "smart enough" to go to college. Hearing this saddened me because I felt that being an educator there should be something I could do to help them. I thought that maybe if I could research the literature and conduct a study that I would be able to shed some insight into this sad situation and use what I had learned to improve to make the academic community aware of what the English Language Learners' circumstances are.

\section{Data Collection Field Notes}

I selected my participants by asking my sister, Mariana, (who also taught ESOL) if she had any former students who might be interested in participating in the study. I told her the criteria they needed to have like being 18 and over, Hispanic, and being a student in college. I told her and others who helped me look for participants that I preferred freshmen college students, but that if they did not know of any, I would determine if they could participate in the study on a case-by-case basis. She referred me to one of the participants, and I also had my friend, Jose, refer me to two other students. I asked one of my colleagues, Monica, if she could refer me to some college students, and she also helped me by referring me to two of them. My former student, Hellen, referred me to three of her friends who had also been former students of mine. She was not able to participate because she was not attending college at the time, but I was grateful that she could help me. Peggy, a friend of mine whom I went to high school with, is active in working with undocumented immigrants, and was able to refer me to two undocumented immigrants. I was very appreciative of this because I wanted to learn about the experiences of those who not only had to learn a new language and customs but struggle twice as much due to their undocumented status. 


\section{Participant 1: Rosa}

I was put in contact with Rosa through my sister. She had been one of her high school students. I interviewed her over the phone and was impressed by how mature and articulate she sounded. She told me about arriving here to Miami from the age of 2 with her parents from Cuba. Even though she arrived here at such a young age, she only spoke Spanish at home, so she was place in ESOL classes. She said that the only English she knew was from "watching TV." She felt that her teachers from South Hialeah Elementary were "very encouraging" and gave her "a lot of self-confidence." Rosa remained in the ESOL program until fourth grade, when she was exited to the regular program. Her family came to Miami for financial reasons, but since she was so young, she doesn't remember who helped her family with the transition from Cuba. She says that her high school teachers and counselors encouraged her to go to college.

At the University of Florida, she began as a full-time student at the age of 18. She was working part-time. She felt "overwhelmed" in college because she had to adjust to being around white people because she had lived in Hialeah her entire life. She believes that she struggled as a freshman due to her poor study techniques, lack of money and friends. Rosa is a political science major at U.F. She believes that her second-grade teacher, history and psychology teachers at high school helped her academically and provided encouragement. In high school, she felt that it was "very competitive," in her Advanced Placement and Honors classes. She was "pushed" to apply to college. Because her parents never went to college, they could not provide all the help she needed. Rosa's academic strengths are planning, prioritizing, analyzing text, and anything language related. She is also minoring in German due to her ability to learn languages. She has taken advantage of resources at U.F. like tutoring and receiving help from professors during their office hours. Rosa's academic weakness is procrastination, but she has learned to "work smarter." She finds her procrastination "a hindrance" in her math and science classes but hasn't wanted to seek help for it due to lack of time and finding it "tough to admit weakness." As part of her extracurricular activities, she has been campaigning with other students and motivating them to vote. She's also very involved in church in Gainesville. At UF, she interacts with friends and classmates. Even though she didn't encounter any big obstacles in college, she feels that she lost out on the opportunity to take college prep classes at her high school that are offered to students in "richer neighborhoods." Her advice to English Language Learners is to try going to a community college if they are having difficulty with English. However, if their English mastery is good, they should consider going straight to university. They should also be provided with encouragement and someone to push them to take more college credit classes. In five years, she plans on having her master's degree and living here or in Germany. 


\section{Participant 2: Danilo}

I was introduced to Danilo by my friend, Jose. I interviewed him over the phone because he is living on campus at the University of South Florida. Danilo arrived from Cuba when he was 11 years old. He was placed in ESOL classes in middle school. His parents came to the United States in search for a better life. He said that his family was not helped with the transition here.

He began attending the USF as a full-time student and worked part-time. He experienced the transition of living in a new place and new style of life academically. Danilo's goal is to go to medical school. He took all the prerequisites in high school to prepare for college. Danilo's academic strengths are English, Spanish and writing papers. He thinks that there is a major difference between high school and college because there is more homework and research, so it is necessary to take time to study. He finds that study groups with his peers are more useful than asking for help from his professors. According to Danilo, math and time management are his academic strengths. At this time, he is volunteering at a health clinic. He also participated in an organization called Emergency and Response, that was a great experience for him. Danilo believes that his parents' divorce when he started college had a negative impact on his college experience because he had just begun college. Working with the paramedics was very helpful in terms of experience but "took time away from his studies." Danilo also felt insecure about not being accepted to the school he wanted, and had felt like giving $p$. He says that he also feels this way when he gets a lower score on a test. He deals with his insecurities by "staying focused and being patient." Danilo's advice to English Language Learners is to "just get out there and not stay in your comfort zone. Just really trying to learn the language by getting really involved." Five years from now, Danilo hopes to be finishing school and moving to a state or country that fits his needs and settling down.

\section{Participant 3: Mayra}

I knew Mayra because she was a former ESOL student. She was an excellent student when she was in my class, and always went above and beyond what was asked of her on assignments, like making extra revisions of her work. I knew that her plans had been to go to college and study medicine, so I was able to message her through Facebook and ask her if she wanted to participate. She agreed, and she came by her former school after hours for her interview. Mayra told me that she came from Honduras at 14. She went through all the ESOL levels in high school before she was exited as a high school senior. Her father was able to secure a VISA through the lottery to come here, and he believed that it would be a once-in-a-lifetime opportunity for his children to obtain a better education and standard of living.

Currently, she is a full-time student at Miami-Dade College and does not work. She is going to declare a major in Biology. Her belief is that teachers can really help you, even though some of her peers would fight and take drugs. Mayra believes that her circle 
of friends from high school have been supportive in college as well. She remains in contact with her former teachers, such as me. In college, she has also made new friends. Mayra believes that her mother pushing her to do better has helped her to achieve more than her. In fact, her mother has told her that she wants Mayra to do better than she has. Mayra's strengths are reading and writing. "The more you read the more knowledge," she says. She also believes that writing things down helps her to retain information.

According to Mayra, college is harder than high school and the academic strengths needed are different. She has taken advantage of the assistance offered in college, such as study centers and professors' office hours. Mayra believes that she has a problem with procrastination. She says that she feels stressed because she has had to stay up late to make up for lost time. She says, "I study more than in high school." She needs to create study plans to get all her work done on time. Mayra finds that participating in STEM Club and CRU, a religious club are beneficial to her. Her biggest obstacle was having to pay for college and completing all her applications before college. A college advisor helped her to get financial aid. Mayra would advise an English Language Learner to "Prepare yourself more during high school and ask for help with money or anything to an advisor." In five years, Mayra hopes to be in medical school.

\section{Participant 4: Karina}

Karina was also a former student of mine. She was a model student in class, and I admired the way that she would struggle to get her point across by using her Spanish/English dictionary in class to find the right words to express herself. I always thought that she would succeed like Mayra because she learned English in just three years. She was also exited from the ESOL program as a senior. Karina came to the U.S. when she was 14 years old. Her reasons for leaving Honduras for Miami were financial and because "my mom wanted to succeed." Karina says that her mom, dad, stepmom, and grandma helped her transition to the U.S. both financially and emotionally.

She began college as a full-time student who did not work. She said, "I felt nervous because I didn't know anyone." Karina is a first-generation student as well. She plans on majoring in criminal justice. She believes that her peers helped her to feel more comfortable by talking to her and spending time with her. Since Karina is a firstgeneration student, Karina feels that her family has supported her financially and emotionally, but they have not been able to help her academically. Her academic strengths include being good in math, English and science. She uses Google and YouTube for help with her assignments. In addition to using technology, Karina also makes use of study centers and professors' office hours when she needs help. Karina believes that her academic weakness is her English language barrier. Karina does not participate in any college activity. A major obstacle for Karina was obtaining financial aid. Her advice to ELLs is: "If you want it that bad you can do it. Be open to learn and feel vulnerable." Karina sees herself with a stable job in Customs and a family in five years. 


\section{Participant 5: Oscar}

Oscar agreed to participate in my study. He is a former student of mine. My impression of Oscar was how proper and mature he was for his age. He was very hardworking and respectful. Oscar told me that he arrived at Miami when he was 13 years old. He did not know any English, but he managed to exit ESOL in his senior year as well. His reasons for leaving Nicaragua included better educational opportunities and to be a professional. His parents supported him with his transition to this country. He attends college full-time and works part-time. He has regular English classes. He does not interact with anyone in college. One teacher that helped him was Ms. T who "made me believe I could do it." Ms. K also believed he could do the work. Oscar also gives credit to his friends because they "inspired me to get through the process." His parents also helped him by providing motivation and support. Oscar's academic strengths include math and science. He also does not procrastinate on his assignments. He received assistance with taking the SAT and ACT. He mentioned that he does not have time to ask for help with his classes. He mentioned English as an academic weakness. He does not participate in extracurricular activities. An obstacle to his studies was that he was working full-time when he first started taking classes. His advice to ELLs is "Do not be afraid to get help. Language is not an obstacle because you can get help." Oscar plans on working for a company and building towers once he is finished with his mechanical engineering degree.

\section{Participant 6: David}

I was able to recruit David through his mother, who is my manicurist. I interviewed David at home, where he lives with his parents while he studies psychology full-time at Florida International University while he works part-time. David is very interested in psychology and why people are motivated to act the way they do. David arrived at Miami from Cuba when he was 11 years old. When he began attending school, he knew some English because he had learned some English in Cuba. His parents were looking for better educational options for him and his older sister, so they decided to come to Miami. They were able to take advantage of the Cuban Adjustment Act, also known as "Wet Foot, Dry Foot," which offered them a good benefits package.

He began his studies at Miami-Dade College as a part-time student while working full-time. After graduating with his associate's degree, he went to Florida International University. He is now working part-time and majoring in psychology with a Japanese minor. As a middle school student, he was motivated by the teacher who said that they have to look beyond, and not label themselves as ESOL, to trust themselves. He does not interact much at FIU, but does interact with others in his Japanese classes. David feels that his parents provided him with support and guidance, but could not help him navigate college. His academic strengths are analyzing information and writing. He is also easily able to memorize and retrieve information. David utilizes the resources available to him such as the library, counseling, research labs, and financial aid. He did point out that he 
did not have time to ask his professors for help. His academic weaknesses include math, public speaking, and dealing with anxiety. Due to time constraints, he also does not participate in extracurricular activities. Because of his difficulties with math, David struggled to pass his remedial math classes. He advises ELLs to "read as much as they can.” In five years, David plans to be working as a clinical psychologist.

\section{Participant 7: Charles}

I met Charles through his girlfriend, who is a former student of mine. Charles interviewed with me over the phone. He came across as a shy young man. Charles came to the U.S. at 18 from the Dominican Republic. He graduated with an ESOL 2 or 3 level; he does not remember. He arrived at Miami looking for a better financial future and the unemployment in his native country, and his father helped him with the transition. Charles began studying Miami-Dade College part-time while studying part-time. He studies in the afternoon. Charles feels that his college experience has been enjoyable, but it is "a different world." Charles plans on majoring in architecture, and he believes that his ESOL teacher from high school, Mr. A., taught him reading and writing skills in English. His math teacher also taught him a lot. Even though his friends dropped out, Charles felt motivated to continue with his studies. He does not like to spend time with his friends because he feels they are not a positive influence. However, Charles feels that his dad, who is an engineer, is a positive role model because he advised him to study for a better life. When asked about his academic strengths, Charles believes that his reading comprehension is good, and it improves by reading often and watching movies. Charles has not taken advantage of help in college, nor does he participate in extracurricular activities, due to lack of time. His weakness is listening comprehension, and he tries to improve it by watching the news. Charles has not experienced any obstacles in college and has stayed motivated to persist. He encourages ELLs to "Study a lot and always stay motivated." He also said, "It's hard to learn a new language, but even so you can still work hard and stay motivated." In five years, he plans on having a family and a career as an architect.

\section{Participant 8: Estefanía}

Estefania was recommended to me as a participant by one of my colleagues, who is her college professor. Estefania was happy to participate. I had second thoughts about having Estefania participate because she was born in the U.S. However, when I spoke to her, I found out that she did not learn English until she went to school. Therefore, even though it seems that she would not qualify for this study at first glance, she still had most of the characteristics of a foreign-born student. I interviewed Estefania over the phone.

She told me that she had learned English in kindergarten, and she did not have anyone to help her with her homework. Estefania's parents come from different countries; her mother is and her father is. They met in this country. Both of them came looking for a better financial situation and future. Estefania has felt that her college experience has been both positive and negative. She studies part-time and works part-time. She began 
her studies at Broward College, but her experience there was negative because she felt that her professors did not care if their students understood the material or not. This was difficult for her because she had felt intimidated in her earlier school experiences by teachers who were indifferent as well. She now attenders Keiser University and feels that her professors are more patient there. Estefania plans on majoring in marketing. She believes that her English professor "has made me feel better about college." She also mentioned a teacher assistant who helped her in her earlier years. Estefania's friends have had a positive impact on her because they have motivated her to study, especially her cousin, whom she regards as a role model. Since Estefania is a first-generation student, her parents could not help her with the college adjustment process. She believes that her strengths are "English, and anything but math." As far as taking advantage of college resources, Estefania uses Keiser's database to write papers. She does not have time to ask for help. Estefania considers math and having difficulty paying attention to be her weaknesses. She commented that some classes in high school "were a waste of time." Because she works and studies, Estefania does not have time to participate in extracurricular activities. Her obstacles to attending college were failing her math class, having a full-time job, and a lack of time for studying the first time she enrolled in higher education. She also had to leave school for two years to help her parents out financially. This is her advice to ELLs: "Don't be afraid and anything is possible. Hang out with people who can help you succeed and use the resources at school." In five years, Estefania expects to have graduated, be working on master's degree and career, have gotten married, and have children.

\section{Participant 9: Cristobal}

Cristobal is another former student of mine who was willing to participate in the study. As a student, I remember him as being very artistic and funny. He kept a sketch pad with drawings that he would take everywhere and proudly show off. I often told him that he was very talented and that he should make graphic design or architecture his career. He seemed to have listened because he is now in college and has decided to major in architecture. Cristobal was 16 when he came to the U.S. from the Dominican Republic because his stepfather wanted to move and look for a new job and opportunities. Cristobal's cousin helped his family with the transition to Miami.

Cristobal did not know any English when he enrolled in high school, and in the space of three years he could speak it fluently. Cristobal's experience at Miami-Dade College was negative at first because he was working full-time and it was too much. $\mathrm{He}$ decided to quit working and dedicate himself to his studies. Presently, he is taking nine credits. His architecture class is very challenging because his professor is a perfectionist and does not tolerate errors of any kind. Cristobal said that he "felt weird and isolated because no one talks to you." Cristobal feels differently about his high school experience because he said that "teachers helped me to feel more comfortable. Work was easier than in college. In college, you have to be responsible. Nobody's gonna care." Despite his 
feelings of isolation in college, he was able to keep the friends who helped him adapt to high school, and now have supported him in college. He also commented that his girlfriend was his role model. Cristobal also credits his mother for continuing his studies because she encouraged him and told him that "he had to be responsible if he wanted to be somebody." According to Cristobal, his academic strengths are making lines and measurements. The resources he uses most in college are the virtual library at school for essays as well as Google. Cristobal's weakness is getting distracted easily and not having enough time to finish tests. He has not sought help for his weaknesses. Cristobal does not participate in extracurricular activities because he finds his classes challenging. $\mathrm{He}$ believes that the obstacles that he encountered at first were solved by quitting his job because it was too difficult to juggle both work and studying. His advice to ELLs is: "Speak English." In five years, Cristobal would like to see himself in a big university countinuing his career.

\section{Participant 10: Lorenzo}

My friend Peggy introduced me to Lorenzo, due to her volunteer work with Immigrants Without Borders. I interviewed Lorenzo over the phone, and he told me that he left Mexico when he was seven years old. I found Lorenzo to be very articulate and easy to talk to. I found his interview to be very helpful because it gave me some insight into the experience of the undocumented immigrant. I felt proud that he felt comfortable enough to talk to me despite his circumstances and that he was willing to take a risk and share his experience.

Lorenzo told me that he didn't know any English and was exited from the ESOL program when he was in the fourth grade. His family decided to leave their country because they were struggling financially. Lorenzo is a first-generation college student, and he found his experience in college to be "real exciting. It had a lasting impact that would open doors for me." Lorenzo's intent is to study marketing. He credits DACA with "giving him the hope to go to college." Lorenzo first came to Broward and found that his teachers were supportive when he was struggling. His fourth grade teacher was especially supportive because he recognized Lorenzo for his efforts and made him Student of the Month. His experiences with students in his elementary school was mixed however; in the second grade he found a friend who would translate for him, but he was also bullied in school. In the sixth grade, some students helped him feel welcome.

In his college experience, Lorenzo found that group chats and emailing his professors was useful to doing well in his class. His family also was a source of support for Lorenzo because he was able to support himself by working with them. He described his family as being stable and supportive. Lorenzo feels that his strengths are his excellent communication skills, and his organizational and analytical skills. Lorenzo said, "In college you have to be more disciplined and there's more group projects. I've learned to plan for every test on the calendar." Lorenzo does not use the college resources available to him. Procrastination and math are Lorenzo's weaknesses. These weaknesses 
have hindered his progress because he failed a precalculus class. Despite his busy schedule, he finds time to volunteer for an important cause which is Students Working for Equal Rights. However, he does not interact often with people from his classes. His major obstacle to attending college was his undocumented status. Due to his status he was forced to pay international rates. He was initially a part-time student, but now he is studying full-time. His advice to ELLs is: "it is definitely important to not only take classes but make friendships and form relationships with English speakers. It's problematic in South Florida that a lot of people immigrate here and surround themselves with people who speak their language." Lorenzo said that he would be graduating this December. He said that he would like to do volunteer work and be a marketing consultant.

\section{Participant 11: Gisela}

I met Gisela through my friend Jose. Gisela was also born in the U.S., but I thought that she could be a participant because like Estefania, she did not speak English when she started school. I interviewed Gisela over the phone, and she gave me the impression of knowing exactly what she wanted and being mature for her age. Gisela's parents immigrated from Cuba before she was born. Her grandmother and cousin helped her parents adjust to the U.S. Gisela learned English in first grade. Her fourth-grade teacher helped her to adapt. She felt that her elementary school program "was very helpful with Extended Foreign Language Learners." Her high school experience was very different because she was enrolled in the Cambridge Program, which is an honors program. Gisela remembers "I couldn't count on friends from the Cambridge Program in high school because I couldn't trust them. Now I barely talk to them." Gisela considers her mother to be her role model because she has "always been an inspiration. She always told me to get good grades. She was always very hard on me."

When asked about her academic strengths, she considers writing, grammar, and her dedication to interests like yearbook to be her strengths. She has taken advantage of college resources by participating in the Honors Program at Santa Fe College. She finds the math lab "very helpful." Gisela's biggest weakness is procrastination. She bought a planner to help her with this issue. She feels that it's hindered her because she "starts things at the last minute." She feels that her planner has helped her so far. Gisela participates in extracurricular activities such as Student Life and Public Speaking Clubs. At University of Florida, she is currently a member of the Advertising Club. Her biggest challenge has been financial. Gisella stated, "My family doesn't have a lot of money, so I have to work. The financial aid is not enough." Her advice to ELLs is: "Keep practicing, practice speaking skills, and do not procrastinate." Gisela expects to be a UF graduate and working for an ad agency in New York or California in five years. 


\section{Participant 12: Gregorio}

I selected Gregorio as a participant because he was a former student of mine who met the criteria. Gregorio left Honduras when he was sixteen years old because he and his family were looking for a better future and economy. He spoke no English and went up to ESOL 3 in high school. In interviewed him over the phone because he has a very busy schedule. Gregorio found that his teachers were very helpful in his transition to Miami. Gregorio believes that his ESOL teachers were especially supportive because he only had a sixth-grade education when he left Honduras. He also made many friends in high school who helped him speak English. His mother has been a very positive influence in his life and his role model because she encouraged him to go to college.

Gregorio's first experienced in college was positive because he knew English. He is a part-time student and works part-time. He is a first-generation student as well. Gregorio still does not know what he wants to major in. Gregorio's academic strengths are; math, excellent study habits, and asking a lot of questions. Gregorio does not take advantage of college resources. He feels that English is his academic weakness, and the language barrier caused him to feel scared when he started school in Miami. Gregorio does not participate in extracurricular activities. He considers the lack of money to pay for classes to be his biggest obstacle. He advises ELLs to "Practice your English. You have to always do your homework." Gregorio hopes to have a good job, his diploma, and a family in five years.

\section{Participant 13: Sofia}

My colleague put me in contact with Sofia. When I interviewed Sofia, I felt a great admiration for her motivation to succeed against all odds. I spoke to her over the phone, but the energy in her voice was contagious. Sofia told me that she had immigrated from Peru at fifteen. Her family decided to leave Peru because they wanted a better future and she could not live there by herself. Her mom's best friend helped them to adapt to Miami. She knew no English when she arrived so she placed in ESOL classes. In school, the teachers forced her to speak English. They felt that that was the only way to learn. Sofia felt that all her teachers wanted her to learn. Her tenth-grade ESOL teacher would even stay after school to help her with her English.

Sofia's path to a higher education has not been easy. She has had to begin her pursuit of a college degree three times. The first time she studied at Miami-Dade College was at twenty-five. She went for two years, but had to stop because of work. The first time she began her studies her ambition was to be a dentist or a dental assistant. The second time she went to college she went to a technical school, but wasn't able to continue. The third time, she decided to go to Keiser University and study respiratory therapy. She works full-time and also attends classes from 6:30-10:30 during the week. She has a very hectic routine because she has to pick her children up every morning from her mother's house where they sleep over during weekdays, and take them to school. 
Then, she drives to work, and works fromm 8 a.m. to 5 p.m. She considers her mother her role model because she remembers her mother taking her to the university when she was little when her mother was studying to become a dentist. Sofia feels that she cannot disappoint her mother. Sofia's academic weaknesses are math, and she is very concerned that she will not be able to pass college algebra. She would like to go to tutoring, but she doesn not have time to go, so she relies on YouTube and Google to help her study for math. Sofia finds that Keiser University is very fast-paced. She is thankful that her strength is having an excellent memory that allows her to memorize large chunks of information in a short amount of time. She does not participate in college activities because she is too busy with work and family responsibilities. Sofia interacts with her friends over the phone. She believes that the obstacle to study was having a family early on and not putting forth her best effort. Her advice to ELLs is "to tr and do it. It's the only way to learn." Five years from now, Sofia expects to be working at a hospital and being happy.

\section{Participant 14: Rafael}

My friend Peggy referred me Rafael for my research study. I interviewed Rafael by phone and it struck me how passionate he was about helping other undocumented immigrants. He is very active in the cause of reuniting immigrant children who have been separated from their parents.

Rafael immigrated from at the age of twelve from Peru. He started in the ESOL program in middle school, but was in the Honors programs in high school by the time he graduated. In the seventh grade, one of his teachers was very helpful. He was active in high school because he met friends on the football team and ran for Student Government. He said, "I'm still friends with my best friend from high school." He had a supportive counselor who encouraged him to apply for college.

When he began Miami-Dade College, he "felt very weird because I knew my situation was unique to my immigrant status." He feels that Miami-Dade College President Padron has been instrumental to helping the Dreamers. He also received encouragement from his dad, who is an engineer. Rafael is a mechanical engineer major as well. Rafael believes that he is capable in all subject areas, except for writing. He uses the tutoring services at the college when he can. Rafael is active on campus with the Society of Hispanic Engineers, Engineering Club, and the Counselors' Advocacy for the Advocacy of Immigrant People. Challenges that Rafael had to face when he first began college include having to change jobs, helping his sister begin school, his parents' divorce, and his grandmother suffering from Alzheimer's in Peru. His advice to ELLs is to "Find any way, shape, or form to practice the language." He also advises them to "explore the option of honors and AP classes because they open the doors to opportunities." After having spent ten years in college, Rafael expects to be working as an engineer in five years. 
VITA

\section{GABRIELA DE FRANCISCO}

\section{Born, New York, New York}

gdefr001@fiu.edu

$1988 \quad$ Bachelor of Arts, English

Spanish minor

1993 Master of Science, TESOL

University of Miami - Coral Gables, Florida

2015-2019 Doctoral Candidate for Adult Education/Human Resource Development Florida International University-Miami, Florida

Certified in ESE K-12, 2016

Miami-Dade College ESOL instructor, 2002-2014

University of Miami MSTESOL Grant, 1990

Certified in English 6-12, ESOL K-12, Spanish 7-12, $1989-2019$

United Teachers of Dade Member, 1989-2019

Recipient of Coca-Cola Scholarship, 1984 